\title{
Characterization of Defects and Stress in Polycrystalline Silicon Thin Films on Glass Substrates by Raman Microscopy
}

\author{
Kuninori Kitahara, Toshitomo Ishii, Junki Suzuki, Takuro Bessyo, and Naoki Watanabe \\ Interdisciplinary Faculty of Science and Engineering, Shimane University, 1060 Nishi-Kawatsu, Matsue 690-8504, Japan \\ Correspondence should be addressed to Kuninori Kitahara, kitahara@ecs.shimane-u.ac.jp
}

Received 15 June 2011; Accepted 1 August 2011

Academic Editor: Jin Zhang

Copyright ( $\odot 2011$ Kuninori Kitahara et al. This is an open access article distributed under the Creative Commons Attribution License, which permits unrestricted use, distribution, and reproduction in any medium, provided the original work is properly cited.

Raman microscopy was applied to characterize polycrystalline silicon (poly-Si) on glass substrates for application as thin-film transistors (TFTs) integrated on electronic display panels. This study examines the crystallographic defects and stress in poly-Si films grown by industrial techniques: solid phase crystallization and excimer laser crystallization (ELC). To distinguish the effects of defects and stress on the optical-phonon mode of the Si-Si bond, a semiempirical analysis was performed. The analysis was compared with defect images obtained through electron microscopy and atomic force microscopy. It was found that the Raman intensity for the ELC film is remarkably enhanced by the hillocks and ridges located around grain boundaries, which indicates that Raman spectra mainly reflect the situation around grain boundaries. A combination of the hydrogenation of films and the observation of the Si-hydrogen local-vibration mode is useful to support the analysis on the defects. Raman microscopy is also effective for detecting the plasma-induced damage suffered during device processing and characterizing the performance of $\mathrm{Si}$ layer in TFTs.

\section{Introduction}

Raman microscopy has been used in the field of semiconductor technologies to characterize lattice defect, damage, and stress introduced during crystallization and device processing. Amorphous silicon (a-Si) films and polycrystalline silicon (poly-Si) films on glass substrates have been extensively researched for application as thin-film transistors (TFTs) integrated on liquid crystal display (LCD) panels. The use of poly-Si instead of conventional a-Si allows for highdefinition LCD and the integration of driver circuits into the panels [1]. The primary advantage of poly-Si is the electron and hole mobility at least two orders of magnitude larger than those of a-Si. Poly-Si TFTs are also applied in organic light-emitting diode panels. In the future, the applications of the thin-film poly-Si technology will extend to flexible displays, microprocessor-display-combined devices, and solar cells.
Poly-Si films on glass substrates are generally fabricated by the recrystallization of an a-Si precursor. The recrystallization is industrially performed by solid-phase crystallization (SPC) or excimer laser crystallization (ELC) $[2,3]$. Using these techniques, the film quality is degraded by large density defects due to the seed less growth and restriction of growth temperature. Moreover, stress is caused by the differences of the film and substrate materials. Thus, characterization of the defects and stress is indispensable for the development of crystallization and device-processing technologies.

Raman scattering spectroscopy enables nondestructive and easily operable microscopic characterization for a large area panel. The major tool in Raman spectra for the characterization of poly-Si films is a peak corresponding to the single optical-phonon mode (OPM) of the Si-Si bonds. However, the analysis must be carefully performed because a variety of information is contained in the single OPM band. 
Mapping of Raman spectra is a useful technique to analyze the nonuniformity and grains of the film. The local-vibration mode (LVM) of the Si-hydrogen $(\mathrm{H})$ bonds is also available to characterize defects because the dangling bonds at defects are easily terminated by $\mathrm{H}$.

In this work, we will describe the characterization of SPC and ELC poly-Si thin films on glass substrates. First, the geometry of the grains and defects is shown using electron microscopy. Next, an analysis of the stress and defects is performed via the Si-Si OPM. Two-dimensional mapping is used to assist in the characterization. The intense Raman scattering observed for ELC films is related to their proper surface morphology. The defects observed by electron microscopy and Raman microscopy are compared with each other. The Si-H LVM is used to characterize the defects at the grain boundary and ingrain. Raman microscopy is also applied to characterize the plasma damage during device processing and the performance of Si layer in TFT structure.

\section{Experimental Procedure}

Either low-alkali glass or synthetic quartz glass has been used as a substrate for LCDs. In this experiment, the latter was used as the substrate because of its high strain point of $990^{\circ} \mathrm{C}$, which enables SPC. A silicon dioxide $\left(\mathrm{SiO}_{2}\right)$ underlayer and an a-Si top layer were deposited on the substrates by plasma-enhanced chemical vapor deposition (PE-CVD) or low-pressure thermal CVD. The typical thickness of the a-Si layers was $50 \mathrm{~nm}$.

The industrial techniques for the crystallization of polySi thin films are shown in Figure 1. SPC was performed in an electric resistance furnace at $900^{\circ} \mathrm{C}$ for $1 \mathrm{~h}$ in flowing $\mathrm{N}_{2}$ under atmospheric pressure. ELC was performed using a $\mathrm{XeCl}$ excimer laser, that is, pulsed light with a duration of $\sim 10 \mathrm{~ns}$ and a wavelength of $308 \mathrm{~nm}$. The typical energy density was $350 \mathrm{~mJ} / \mathrm{cm}^{2}$, and the beam overlap during laser scanning was 95\%. Crystallization with an energy density between 200 and $400 \mathrm{~mJ} / \mathrm{cm}^{2}$ was also performed to obtain various ELC films. Super-lateral growth (SLG) [4] and continuous-wave laser lateral crystallization (CLC) [5] techniques were used to obtain films with large-sized grains. SLG was performed by irradiating a-Si with a singleshot excimer laser at an energy density just lower than that required to fully melt the film. CLC was performed on the aSi films by scanning the second harmonics of the $\mathrm{YVO}_{4}$ laser $(532 \mathrm{~nm})$. Nanocrystalline $\mathrm{Si}(\mathrm{n}-\mathrm{Si})$ deposited on glass by catalytic CVD (cat-CVD) was also characterized to provide a comparison for the poly-Si films. The thickness of the film was $150 \mathrm{~nm}$.

Some of the poly-Si films were hydrogenated using a hot tungsten wire as a catalyst to dissociate $\mathrm{H}_{2}[6,7]$. The merits of this catalytic method are that it is plasma-damage free and has a simple setup. The specimen was held at $250^{\circ} \mathrm{C}$ for $3 \mathrm{~h}$ under an $\mathrm{H}_{2}$ pressure of $\sim 10^{2} \mathrm{~Pa}$. Remote plasma hydrogenation was also performed at $350^{\circ} \mathrm{C}$ for $10 \mathrm{~min}$.

The geometry of the grains and defects was observed by scanning electron microscopy (SEM) and transmission electron microscopy (TEM). Secco etching [8] was performed to reveal the grain boundaries prior to SEM.

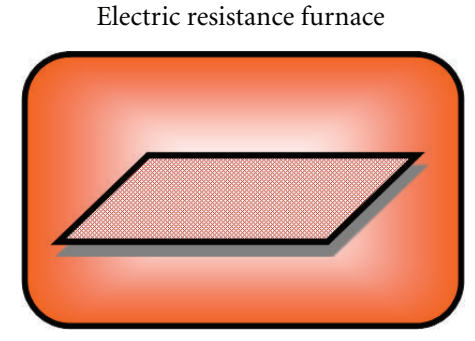

(a)

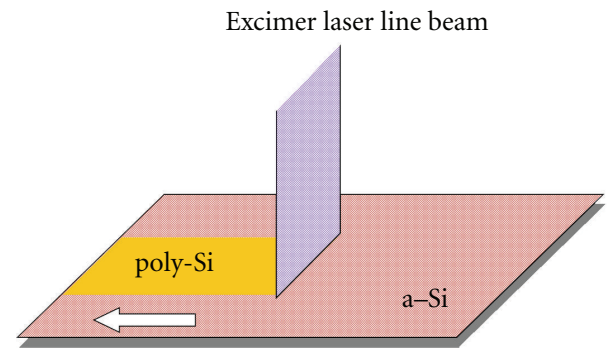

(b)

FIgure 1: Industrial techniques for the crystallization of poly-Si thin films on glass substrates: (a) SPC and (b) ELC.

Raman microscopy was carried out with a backscattering geometry using a $514.5 \mathrm{~nm}$ Ar-ion laser for excitation. Spectral factors such as the full width at half-maximum (FWHM) and peak frequency of the OPM were determined by averaging values of five or more points on individual films. The frequency resolution of the spectrometer was estimated to be $2.3 \mathrm{~cm}^{-1}$. The values of FWHM given in this paper were calibrated with this resolution. Typically, no polarizer was placed in the optical path. However, for the analysis of polarization, the polarization angle of the incident light, $\psi_{i}$, was varied from 0 to $180^{\circ}$ by rotating a half-wave retarder, and Raman scattering was detected with a polarization angle $\psi_{s}$ of either 0 or $90^{\circ}$. The combination of $\psi_{i}$ and $\psi_{s}$ both equaling $0^{\circ}$ corresponds to $x(y y) \bar{x}$ in Port notation [9].

Spectral ellipsometry was performed to analyze the fraction of the crystal component at the initial stage of SPC. In this case, $\mathrm{SiO}_{2}$-coated $\mathrm{Si}\{100\}$ was used as the substrate of the Si films in order to simplify analysis by protecting the reflection from the real face of the substrates. To analyze the spectra of the dielectric constant, the Tauc-Lorentz model [10] was introduced in the optical model.

\section{Geometry of Grains and Defects}

Prior to the analysis of the Raman spectra, the geometry of the grains and defects in the poly-Si films is presented in this paper. SEM images for the SPC film are shown in Figures 2(a) and 2(b). Although little morphology was found for the untreated surface, leaf-shaped grains were revealed by Secco etching for relatively long time where the major twin boundary running along the long axis of the individual grains. The plan-view TEM image for a single grain is shown in Figure 2(c). The grain exhibits a $\{110\}$ surface with a major twin plane $\{111\}$. Moreover, the density of the 


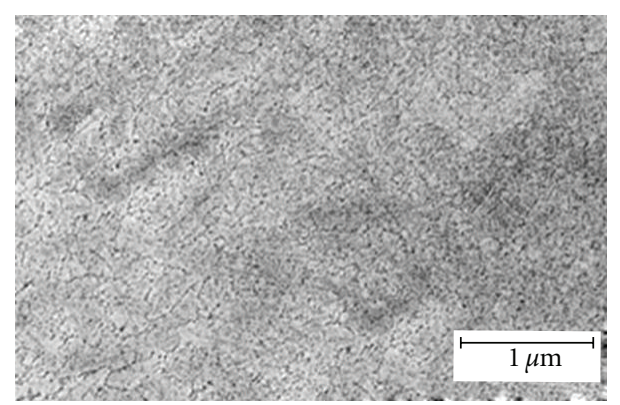

(a) $0 \mathrm{~s}$

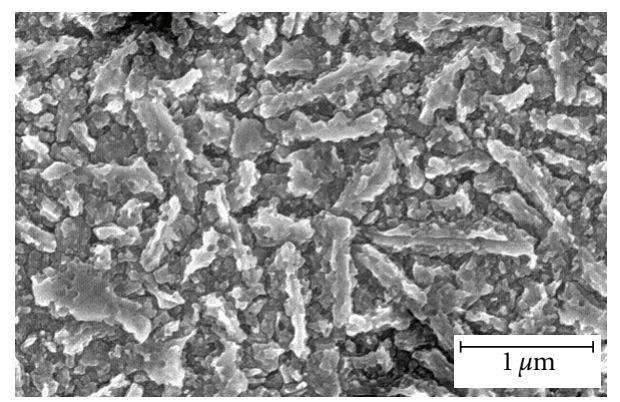

(b) $60 \mathrm{~s}$

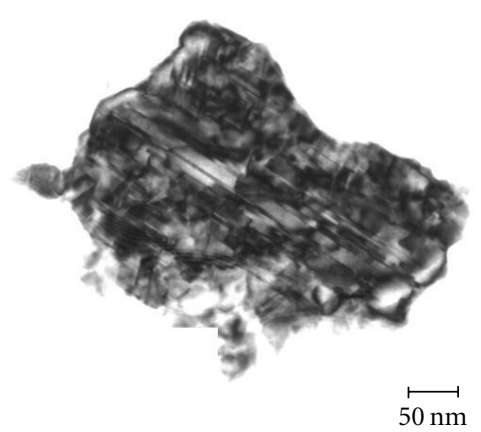

(c)

FIGURE 2: SEM images of SPC poly-Si (a) before and (b) after Secco etching for $60 \mathrm{~s}$ and (c) plan view TEM image of a grain.

microtwins distributed in the grain was high, as reported elsewhere [11]. The intervals of the microtwins are smaller than $10 \mathrm{~nm}$.

SEM images of the ELC poly-Si before and after etching are shown in Figures 3(a) and 3(b), respectively. A large number of hillocks are found on the untreated surface, which is typical for ELC. The averaged interval of the hillocks is $\sim 300 \mathrm{~nm}$, which is nearly equal to the wavelength of the crystallization laser. This morphology of the ELC films was explained by the interference between the surface roughness and subsequent multiple laser pulses [12]. The grain boundaries were revealed as sharp lines after etching. The AFM image for the lightly etched surface shown in Figure 4 indicates that the hillocks are located at the junction of the grain boundaries, and that ridges lay along the grain boundaries. Twin boundaries were found as a shallow line across many of the grains because their electrochemical activity for the etching is substantially smaller than that

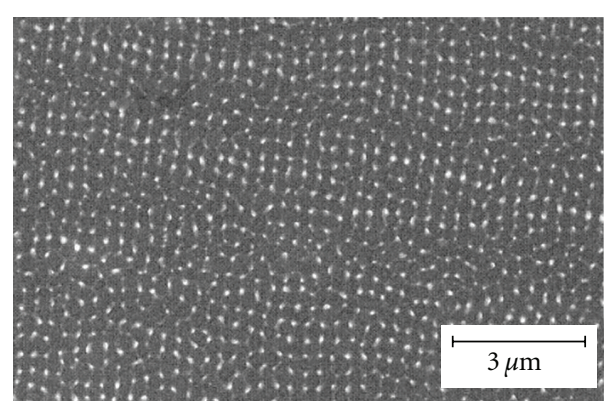

(a) $0 \mathrm{~s}$

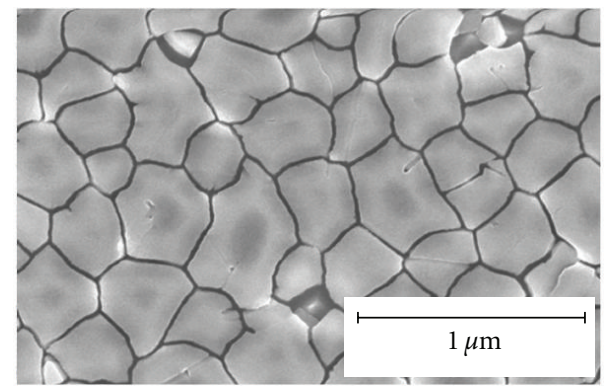

(b) $40 \mathrm{~s}$

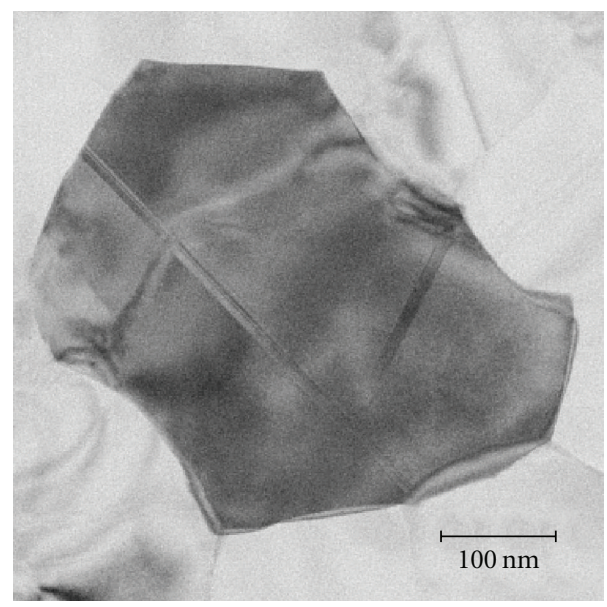

(c)

FIGURE 3: SEM images of ELC poly-Si (a) before and (b) after Secco etching for $40 \mathrm{~s}$ and (c) plan view TEM image of a typical grain.

of grain boundaries. Figure 3(c) shows the plan-view TEM image observed for a grain in the ELC film. The surface orientation is mainly $\{110\}$. A twin boundary crossing the grain and contrasts corresponding to strain due to defect clusters and dislocations were found. However, the density of the observed defects is far smaller than that of the SPC film.

\section{Analysis of Defects and Stress}

The OPM spectra obtained for a-Si, c-Si $\{100\}$ bulk, various poly-Si films, and n-Si films are shown in Figure 5. A single Lorentzian peak was found at $\sim 520 \mathrm{~cm}^{-1}$, which represents the crystalline components in the individual spectra. For nonpolar crystals with a diamond structure like Si, one 


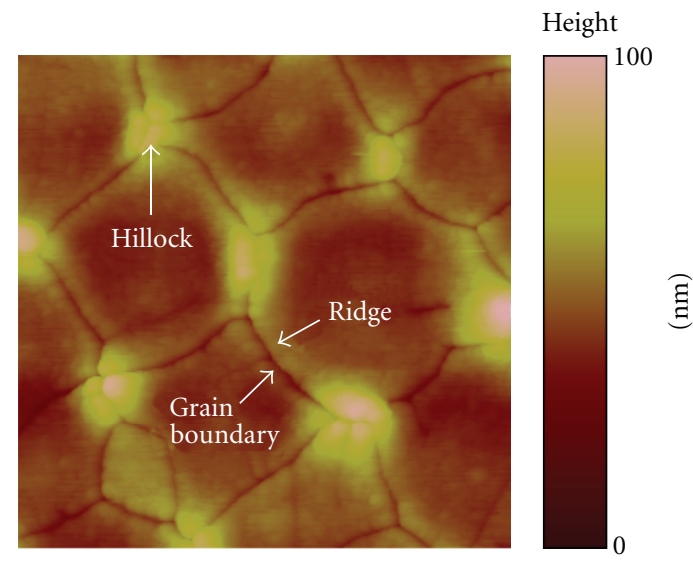

FIgure 4: An AFM image of the ELC poly-Si surface after light Secco etching. The viewing area is $1 \times 1 \mu \mathrm{m}^{2}$.

longitudinal OPM and two transverse OPMs are degenerate with each other and exhibit the same frequency at a wave vector, $\mathbf{q}$, of 0 , which is the $\Gamma$ point in the Brillouin zone. Owing to the conservation of $\mathbf{q}$, the OPM becomes sharp. The phonon frequency, $\omega$, and band shape of the OPM are influenced by strain and defects in the lattice.

When a film consists of nanocrystals smaller than $30 \mathrm{~nm}$, the phonon mode is disturbed resulting in nonuniform in a lattice space. The presence of large-density defects causes the similar effect. A decrease in the phonon correlation length loosens the $\mathbf{q}=0$ selection rule. Therefore, phonons with a wider range of $\mathbf{q}$ contribute to Raman scattering resulting in broadening and a lower frequency shift of the OPM peak $[13,14]$. In the case of a-Si, the conservation of $\mathbf{q}$ is broken, and all phonons on the $\omega-\mathbf{q}$ dispersion curve become Raman active. Therefore, the Raman spectrum of a-Si exhibits broad bands as shown in Figure 5(b) that reflect the density of states of the phonon.

It is pointed out that biaxial stress is contained in polySi films due to the difference in the thermal expansion coefficients of the film and substrate [15-18]. The effective spring constant of the lattice vibration for the phonon mode at the $\Gamma$ point is deformed by the strain of the lattice. The variation of phonon frequency is in proportion with the magnitude of stress. Compressive stress found in $\mathrm{Si}$ on sapphire [19] and tensile stress found in Si on glass result in higher- and lower-frequency shifts, respectively. For devicegrade poly-Si, the crystalline quality should be characterized from the single OPM. In this case, the peak shift reflects both the special correlation and the stress. The FWHM principally reflects the defect density, whereas the effects of stress cannot be neglected when the lattice strain is substantially large and ununiform.

It is expected that the contribution of defects and stress to spectra can be distinguished by semiempirical characterization using data for various films. The relationship between the FWHM and lower-frequency peak shift for c-Si bulk, SPC film, and ELC film is shown in Figure 6. The solid curve in Figure 6 is a value calculated on the basis of the spatial correlation model given in [14]. The plots for ELC with

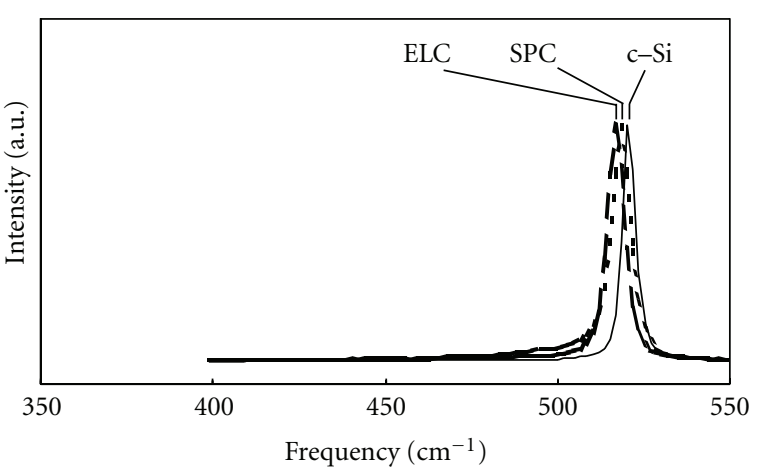

(a)

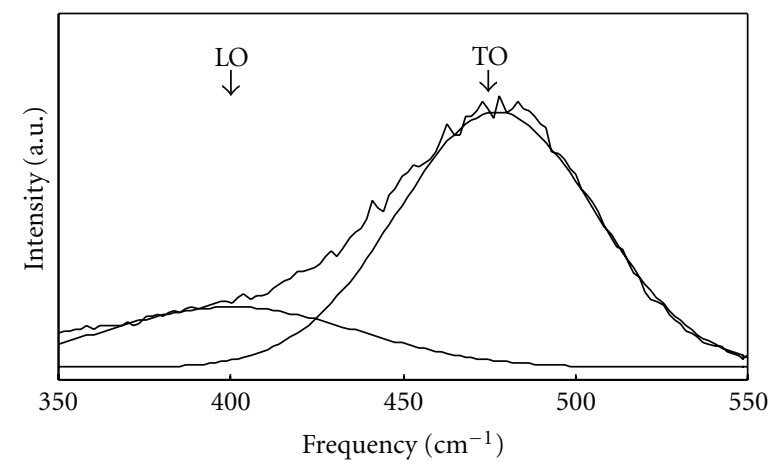

(b)

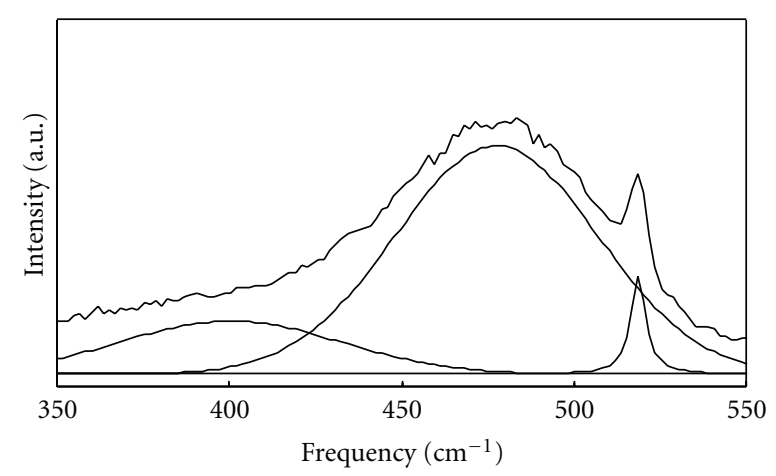

(c)

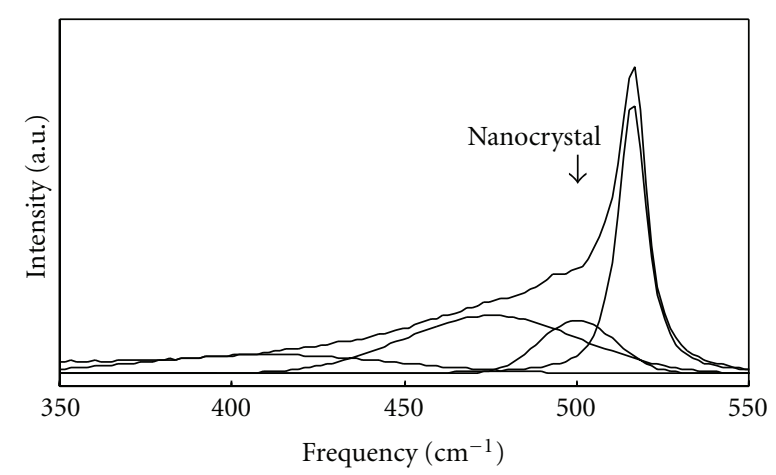

(d)

Figure 5: The OPM observed for c-Si and various Si films; (a) spectra of the c-Si(100) bulk, SPC pol-Si, and ELC poly-Si, with the intensity normalized with the peak height, (b) spectrum of a$\mathrm{Si}$, (c) spectrum of SPC poly-Si heated at $580^{\circ} \mathrm{C}$ for $3 \mathrm{~h}$, and (c) the spectrum of cat-CVD nanocrystalline Si. Thin lines are curves for fitting with Gaussian and Lorentzian function. 


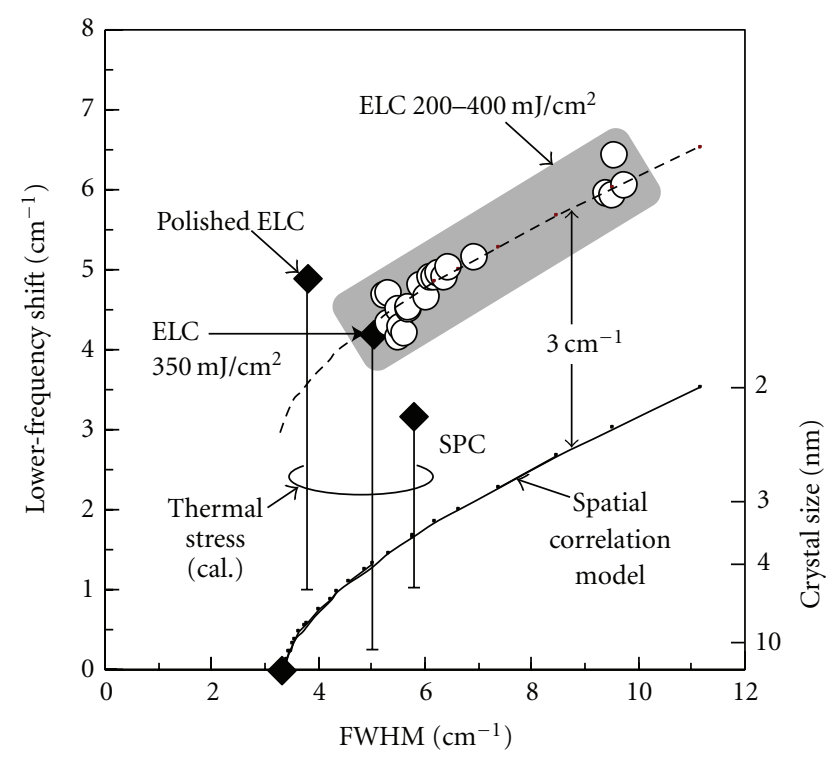

Figure 6: The lower-frequency peak shifts $\Delta \omega$ of the OPM are plotted as a function of the FWHM for $\mathrm{C}-\mathrm{Si}$, SPC poly-Si, and ELC poly-Si. ELC was performed with an energy density between 200 and $400 \mathrm{~mJ} / \mathrm{cm}^{2}$, which are shown with open circles. The curve is the value given in [13]. The magnitude of $\Delta \omega$ due to thermal stress is also shown as "thermal stress (cal.)." "ELC-p" indicates the ELC film with hillocks and ridges removed by mechanochemical polishing.

various energy densities wholly distribute $3.0 \mathrm{~cm}^{-1}$ above the theoretical curve. This deviation is expected to correspond to thermal stress.

The biaxial thermal stress, $\tau_{\mathrm{th}}$, and the peak shift of the $\mathrm{OPM}, \Delta \omega$, are estimated as follows:

$$
\begin{gathered}
\tau_{\text {th }}=\frac{\left(\alpha_{\mathrm{Si}}-\alpha_{s}\right) \Delta \mathrm{T}}{S_{11}+S_{12}}, \\
\Delta \omega=\frac{\tau_{\text {th }}}{P},
\end{gathered}
$$

where $\alpha_{\mathrm{Si}}$ and $\alpha_{s}$ are the thermal expansion coefficients of Si and the substrate, respectively, $\Delta \mathrm{T}$ is the difference between the regrowth temperature or melting point of $\mathrm{Si}$ and room temperature (RT), and the compliance constants, $S_{11}$ and $S_{12}$, for Si are given as $0.7691 \times 10^{-12}$ and $-0.2142 \times 10^{-12}$ $\mathrm{cm}^{2} /$ dyn, respectively [20]. The proportional constant, $P$, is $2.49 \times 10^{9} \mathrm{dyn} / \mathrm{cm}$ [19]. Some of the factors used are not always the same among different publications. Especially for $\alpha_{\mathrm{Si}}$, the differences among them are not small $[15,17,18]$. Moreover, $\alpha_{\mathrm{Si}}$ is temperature dependent [21], thus a mean value of $3.9 \times 10^{-6} \mathrm{~K}^{-1}$ over a temperature range from 300 to $1300 \mathrm{~K}$ was used here. In the case of ELC, $\alpha_{s}$ is regarded as zero because the substrate is maintained at almost RT. Then, $\Delta \omega$ is estimated to be $3.9 \mathrm{~cm}^{-1}$. The value of $\Delta \omega$ for SPC at $900^{\circ} \mathrm{C}$ is estimated to be $2.4 \mathrm{~cm}^{-1}$ by a similar calculation, in which a value of $5.7 \times 10^{-7} \mathrm{~K}^{-1}$ was used for $\alpha_{s}$ referring to Corning's catalogue.

Although the calculated value of stress in the ELC film is somewhat larger than the deviation of $3.0 \mathrm{~cm}^{-1}$ observed in Figure 6, the stress can be released by multiple irradiation of laser. Moreover, the nonuniformity of stress is unnegligible for the ELC film because the stress varies around grain boundaries as described in the next section.

\section{Intensity of the Optical Phonon Mode}

Raman scattering intensity is not always useful to characterize thin films because of its dependence on the optical path adjustment and optical factors of films. However, it can sometimes provide useful information on materials.

The intensities of the OPM for c-Si $\{100\}$ bulk, SPC, and ELC poly-Si films are shown in Figure 7. The OPM intensity of the ELC poly-Si is apparently larger than that of SPC even though the thickness of both films is $50 \mathrm{~nm}$. It is notable that the intensity of the OPM of the ELC film is larger than that of the c-Si bulk which is thick and almost defect-free.

Four factors are considered for the determination of the intensity: (i) resonance Raman scattering, (ii) the polarization effect, (iii) the interference of light in film, and (iv) the surface-enhanced Raman scattering (SERS) effect. The resonance Raman effect for $\mathrm{Si}$ is induced under excitation with visible light, which is applicable to all specimen in the present experiment.

The polarization effect has been both theoretically and experimentally investigated for c-Si films [22]. Figures 8(a)8 (c) show the results for Si $\{100\}$, Si $\{110\}$, and Si $\{111\}$; the intensity is plotted as a function of $\psi_{i}$. The variation with $\psi_{i}$ was especially evident for $\mathrm{Si}\{100\}$. The intensity of the OPM for the $\mathrm{c}-\mathrm{Si}\{100\}$ bulk that is shown in Figure 7 was measured by adjusting the rotational direction of the crystalline axis to obtain the maximum intensity. A similar plot for the CLC film is shown in Figure 8(d), which shows that the grain shape is flowlike with a width larger than a few $\mu \mathrm{m}$. The intensity variation indicates that the examined grain exhibits a surface orientation of $\{100\}$. By changing $\psi_{s}$, it was deduced that the crystalline orientation along the laser scanning direction is $\langle 110\rangle$. Such obvious dependence on the polarization angle was not found for the SPC and ELC polySi films because the grain size is smaller than the excitation light spot, which is typically $0.7 \mu \mathrm{m}$.

In the case of thin films, their thickness impacts the spectral intensity. The variation of the intensity with thickness has been investigated by calculations and experiments for SOS, and the interference of the incident light and scattering light in thin films were taken into account [23]. For ELC poly-Si film on $\mathrm{SiO}_{2}$-coated glass, the variation of the OPM intensity with film thickness was calculated as shown in Figure 9. For these calculations, the refractive indices of the ELC film were determined by spectroscopic ellipsometry [24]. In the experiments, the ELC poly-Si was angle lapped by mechanochemical polish, and the intensity profile was taken along the tilted surface as shown in Figure 10, with an angle as small as $0.006^{\circ}$. The thickness of the resided poly-Si film is also shown in this figure as the distance from the interface. To relate the intensity with the surface morphology, AFM images at three different positions, that is, (a)-(c), are shown in Figure 11. A small peak of intensity appears at thickness of $\sim 10 \mathrm{~nm}$, which is due to the interference corresponding to the subpeak at $13 \mathrm{~nm}$ in the calculated value. It is notable that 


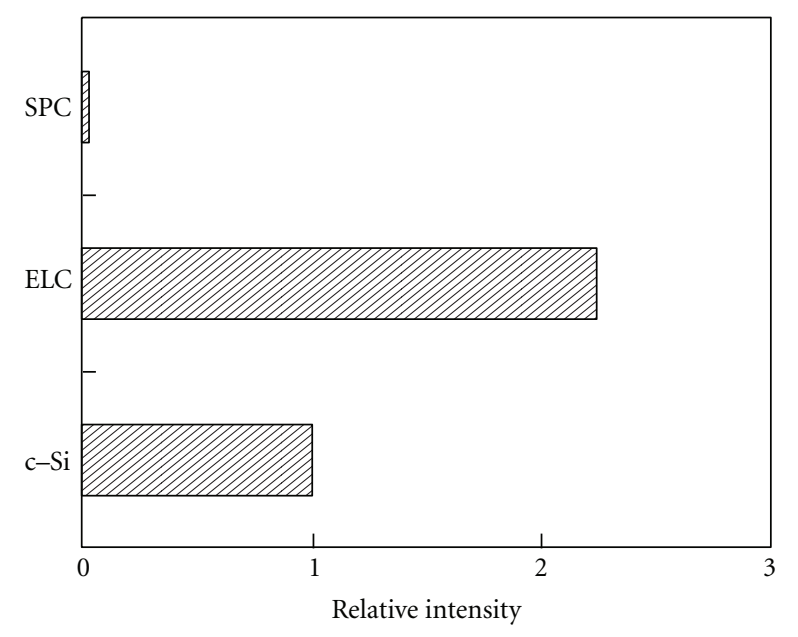

FIGURE 7: Area intensity of the OPM for c-Si $\{100\}$ bulk, ELC poly$\mathrm{Si}$, and SPC poly-Si. The intensity is normalized with that of the c-Si.

the intensity increases abruptly from a thickness of $\sim 40 \mathrm{~nm}$, which is also when the resided hillocks and ridges begin to appear in the AFM image. In the unpolished region, the OPM exhibits an extremely large intensity. The increasing ratio is far larger than the calculated value in Figure 9 in terms of the interference effect. Thus, the effect of surface morphology should be considered when interpreting the intense Raman scattering observed for ELC poly-Si.

Surface-enhanced Raman scattering (SERS) is a typical effect induced by microstructures [25]. The enhancement comes from localized electromagnetic fields resulting from the excitation of localized surface plasmon. It was reported that Raman scattering from molecules adsorbed on roughened silver electrodes was 6 orders of magnitude higher than that from free molecules [26]. The size of roughness that induces SERS can be from the atomic level to a few hundred $\mathrm{nm}$ [27]. SERS was reported also for semiconductors such as heteroepitaxial layers with 10-50 nm roughness and $\mathrm{Si}$ nanocones and nanowires [28-30]. For the Si nanostructures, a strong enhancement $\left(\sim 10^{3}\right)$ of the Raman scattering was observed and explained in terms of a resonant behavior involving incident electromagnetic radiation and the structural dielectric cross-section [30]. Based on these facts, we deduced that the large Raman scattering intensity of ELC poly-Si is attributed to the hillocks and ridges on the surface.

Figure 12 shows the distribution of the FWHM and $\Delta \omega$ of the OPM on the angle-lapped surface. The FWHM increased and $\Delta \omega$ decreased in the area where hillocks and ridges resided. According to the spatial correlation model, an increase of the FWHM should accompany an increase of $\Delta \omega$. Thus, the inverse correlation of FWHM and $\Delta \omega$ is regarded to be properly characteristic for a rough surface.

Since the grain size of ELC poly-Si is smaller than the size of the excitation laser spot, the individual grain boundaries cannot be distinguished by Raman microscopy. However, larger grains can be formed under SLG conditions. Figure 13 shows a two-dimensional map of the OPM taken for the SLG film. It was found that the intensity is enhanced at the ridges and hillocks located around grain boundaries. At these locations, $\Delta \omega$ is relatively small. These results are consistent with those obtained for the angle-lapped specimen shown in Figures 10 and 12. The area with a large FWHM corresponds to a nanocrystal region neighboring large grains. As a whole, it was concluded that the Raman spectra observed for unpolished ELC poly-Si mainly reflect the situation around the grain boundaries. It was also deduced that stress is relaxed around grain boundaries.

\section{Defects Affecting the Optical Phonon Mode}

For relatively high-purity poly-Si films, the FWHM of the OPM was determined to reflect the defect density in terms of the spatial correlation model. However, the type of defect that increases the FWHM was not established. The most direct technique to observe defects is TEM. However, not all defects are observed by the TEM image. Another available technique is Secco etching, which preferentially removes electrochemically active defects and the surrounding area [24]. It is expected that the FWHM of the OPM is decreased by removing the defect-rich area.

Figure 14 shows the variation of the FWHM with Secco etching for SPC and ELC poly-Si with and without hydrogenation. In the case of the ELC film without hydrogenation, the FWHM is decreased by etching. On the contrary for the hydrogenated film, the FWHM was not almost varied by etching, which is attributed to the protection of defects from etching by terminating dangling bonds with $\mathrm{H}$. The TEM image in Figure 3(c) indicates that defect density in grains is far smaller than that for SPC. Thus, it is deduced that the FWHM or ELC poly-Si is increased by defects around grain boundaries which are electrochemically active and not clearly observed by TEM, which is consistent with the result obtained in the previous section.

In the case of SPC, large density microtwins are observed in the grains, as shown in the TEM image in Figure 2(c). The etching increased the FWHM for both as-crystallized and hydrogenated films, which is not consistent with the results for the ELC film. It is noted that microtwins are little active for the etching. Therefore, the increase in the FWHM might be due to the presence of a large defect density in the base layer residing after the etching.

\section{Defects and Si-H Local Vibration Modes}

In general, defects exhibit no proper band in infrared (IR) absorption and Raman scattering spectra. However, the bonding of the defect with an extrinsic light atom sometimes results in LVMs in the spectra. In the case of a-Si or c$\mathrm{Si}$, dangling bonds at the defects are easily passivated by $\mathrm{H}$. Thus, it is expected that the combination of hydrogenation and LVM observation would be useful to detect defects in $\mathrm{Si}$. This section focuses on the $\mathrm{Si}-\mathrm{H}$ bond-stretching mode observed in $2000-2300 \mathrm{~cm}^{-1}$ regions.

Figure 15 shows the Si-H LVM for various Si films; the background was subtracted from the spectra. For a-Si:H, a Gaussian-shaped band at $\sim 2000 \mathrm{~cm}^{-1}$ was commonly found for device-grade films. For hydrogenated ELC poly-Si, both 


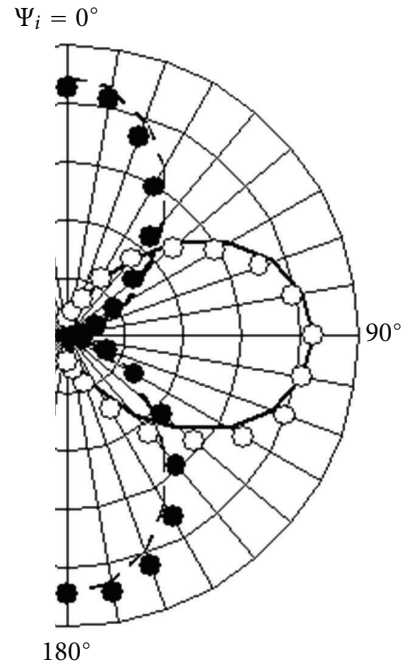

(a) $\mathrm{C}-\mathrm{Si}\{100\}$

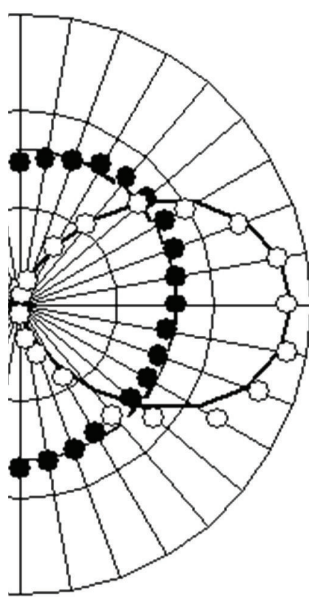

(b) C-Si $\{110\}$

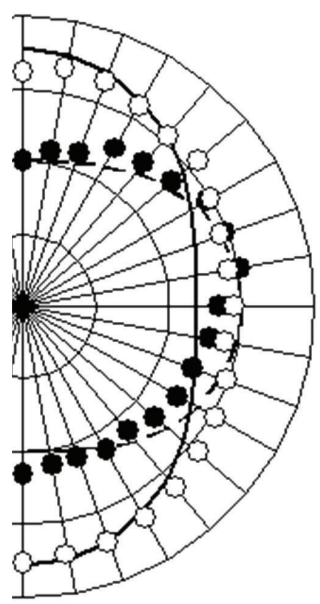

(c) $\mathrm{C}-\mathrm{Si}\{111\}$

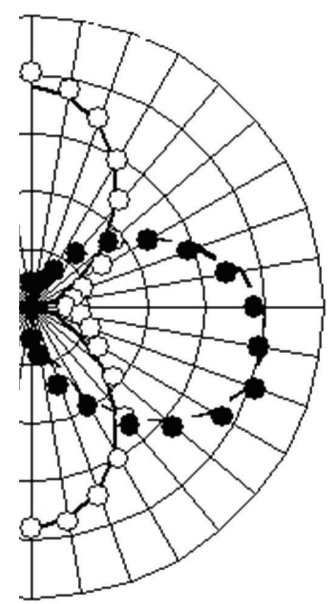

(d) CLC poly-Si

Figure 8: Variation of the OPM intensity for $\mathrm{Si}\{100\}, \mathrm{Si}\{110\}$, and $\mathrm{Si}\{111\}$ with a rotational angle, $\psi_{i}$, of the incident polarized light. The open circles and closed circles are plots for $\psi_{s}=0^{\circ}$ and $90^{\circ}$, respectively.

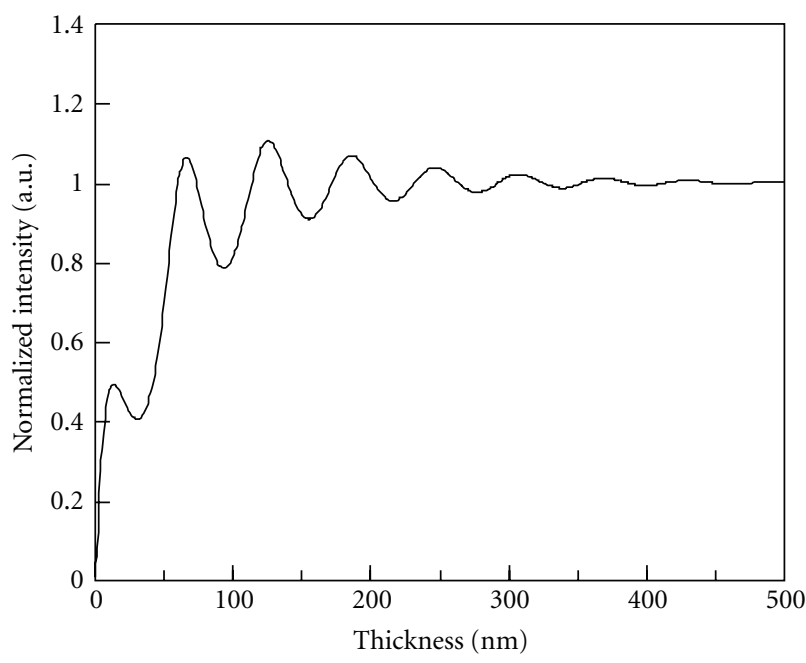

Figure 9: Variation of the $520.5 \mathrm{~cm}^{-1}$ OPM intensity with film thickness calculated for poly-Si film on glass.

a $\sim 2000 \mathrm{~cm}^{-1}$ band and a $\sim 2100 \mathrm{~cm}^{-1}$ band were found, where the former is dominant as long as the hydrogenation is not excessive. On the contrary, for the SPC film, a Si-H band was not almost found even after hydrogenation. Two reasons are considered for the absence of LVM for SPC films. One is the relatively smooth surface comparing with ELC. The other is the low density of dangling bonds in the SPC film owing to relatively high-growth temperature.

In some cases, more LVMs are observed in the spectra. As shown in Figure 15(c), at least four LVMs are found for catCVD film at 2000, 2100, 2170, and $2260 \mathrm{~cm}^{-1}$. The OPMs for the cat CVD film shown in Figure 5(d) indicate that the film consists of amorphous, nanocrystal, and crystal components.

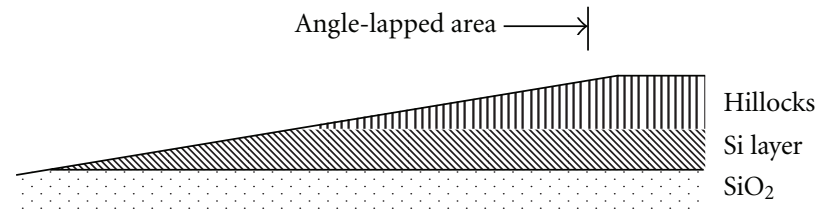

(a)

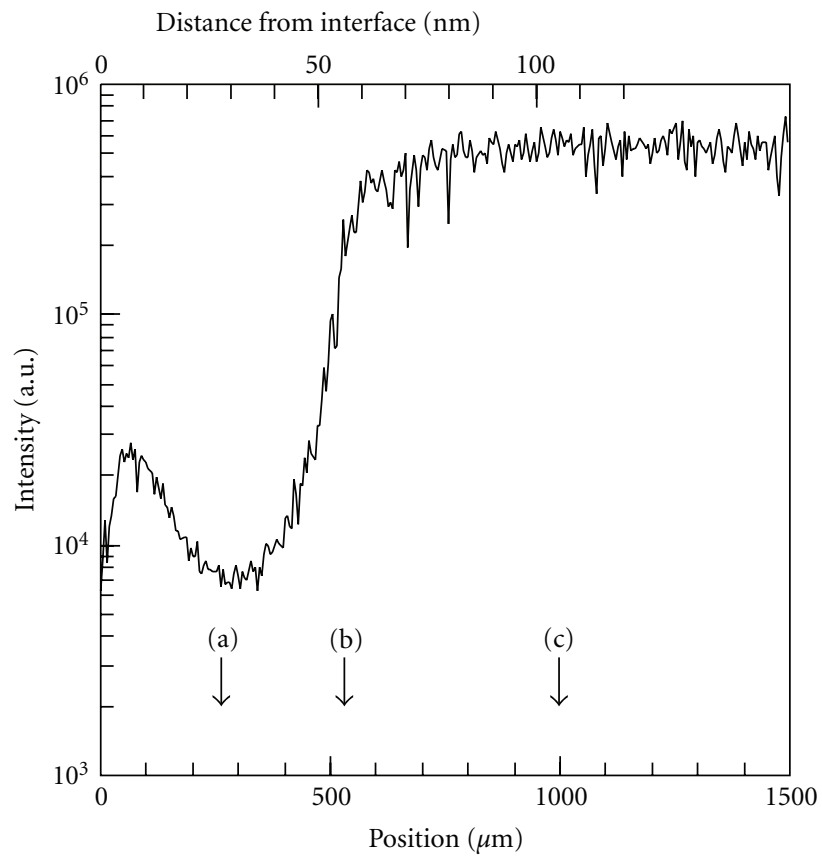

(b)

FIGURE 10: Variation of the OPM intensity with position for anglelapped ELC poly-Si film. The resided Si film thickness, that is, the distance from the interface, is also shown. 

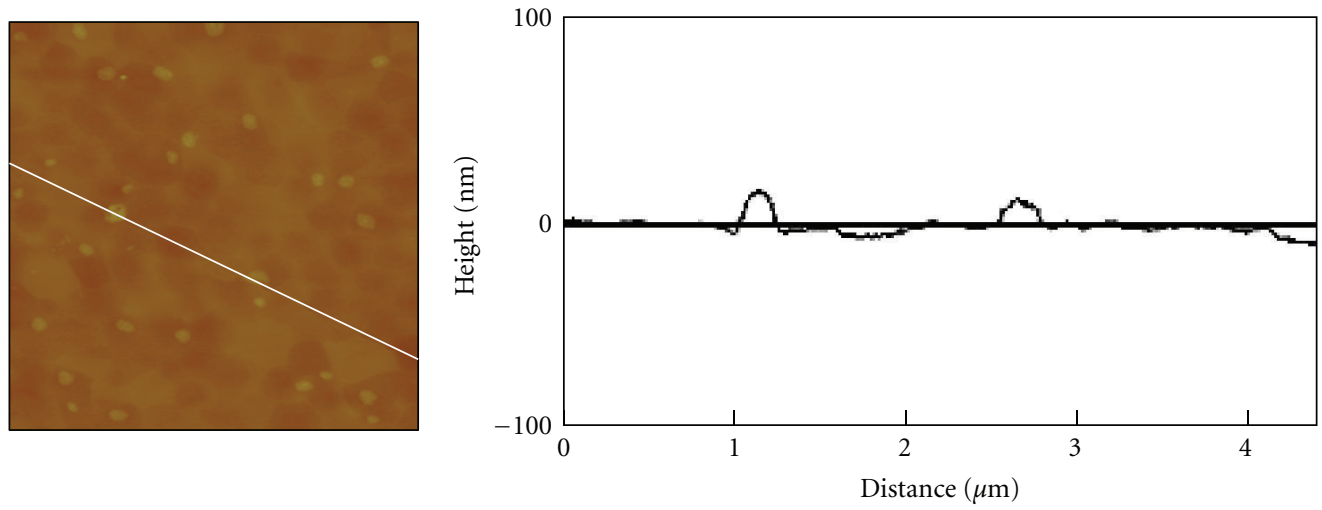

(a)
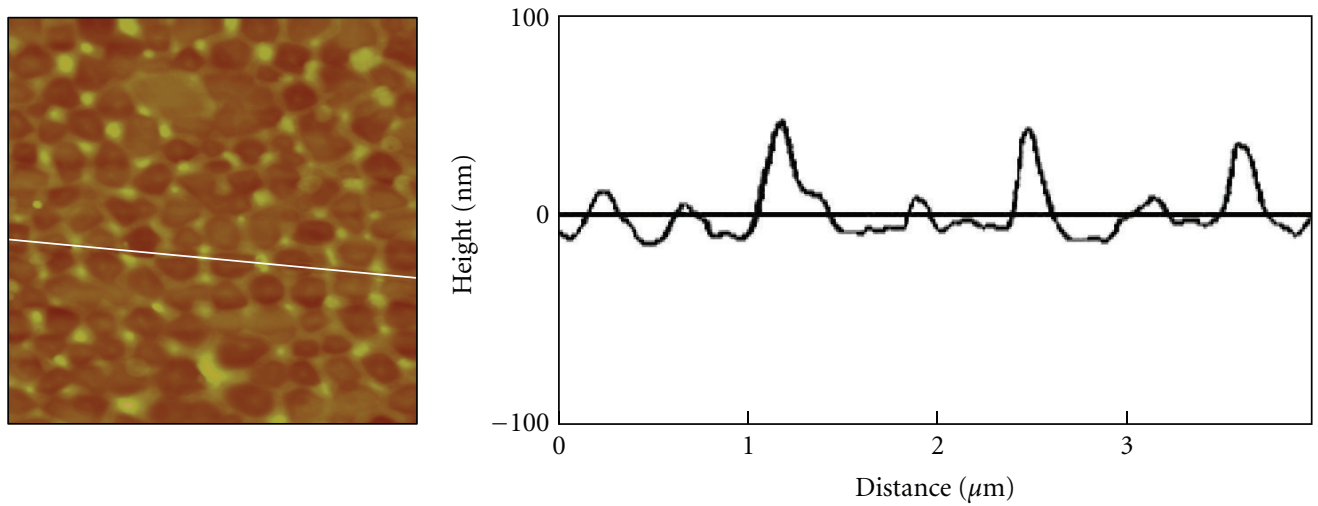

(b)
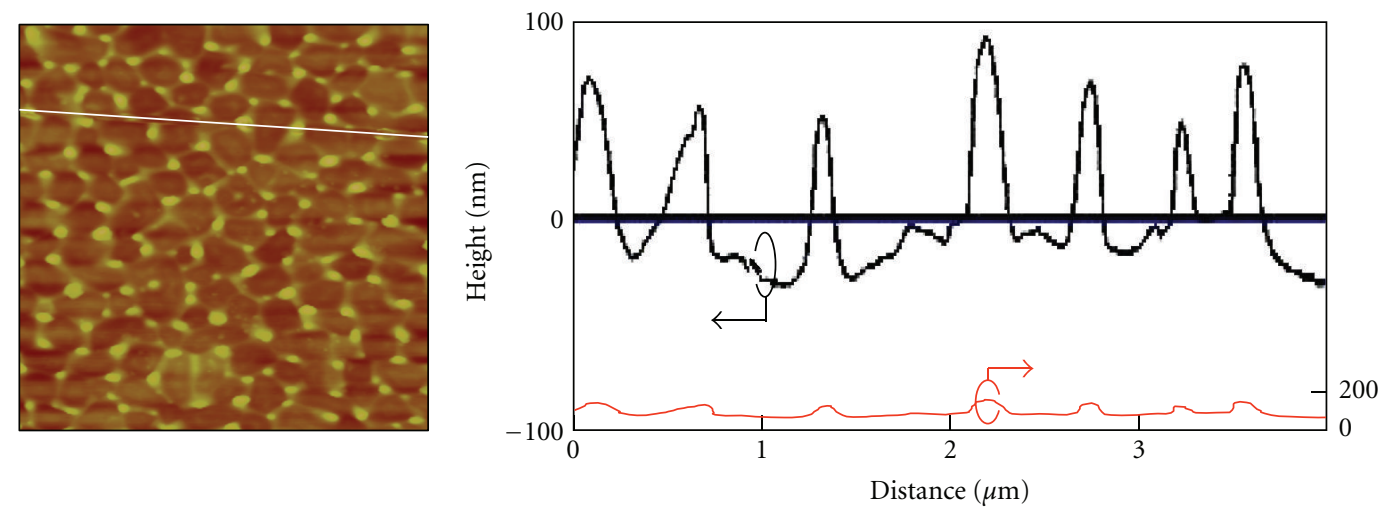

(c)

FIGURE 11: AFM images and profiles of height for positions (a)-(c) shown in Figure 10. The profile shown in the bottom of (c) is obtained by using the same scale for the distance and height.

This suggests that the difference in the frequency of LVM bands corresponds to the different types of structures around the $\mathrm{Si}-\mathrm{H}$ bonds.

In order to relate $\mathrm{Si}-\mathrm{H}$ LVMs to defects in poly-Si, it is useful to give an overview of studies on LVMs for a$\mathrm{Si}, \mathrm{n}-\mathrm{Si}$, and $\mathrm{c}-\mathrm{Si}$. In the case of a-Si:H, many researchers have investigated the origins of LVMs appearing at different frequencies in IR spectra [31-34]. The frequency differences were primarily attributed to the order of the hydrides, that is,
$\mathrm{SiH}_{\mathrm{x}}$, and the structure of the lattice around the hydrides. It was deduced that the $\sim 2000 \mathrm{~cm}^{-1}$ band is attributed to isolated $\mathrm{SiH}_{\mathrm{x}}$ group (predominantly $\mathrm{SiH}$ ) embedded in rather small voids, and the $\sim 2100 \mathrm{~cm}^{-1}$ band is due to clustered $\mathrm{SiH}_{\mathrm{x}}$ group (predominantly $\mathrm{SiH}_{2}$ ) in large voids [34].

In the case of $\mathrm{n}-\mathrm{Si}$ deposited by $\mathrm{CVD}$, an isolated $\sim 2100 \mathrm{~cm}^{-1}$ band or both $\sim 2000$ and $\sim 2100 \mathrm{~cm}^{-1}$ bands were frequently found $[35,36]$. In the case of $\mathrm{c}-\mathrm{Si}$ bulk, 


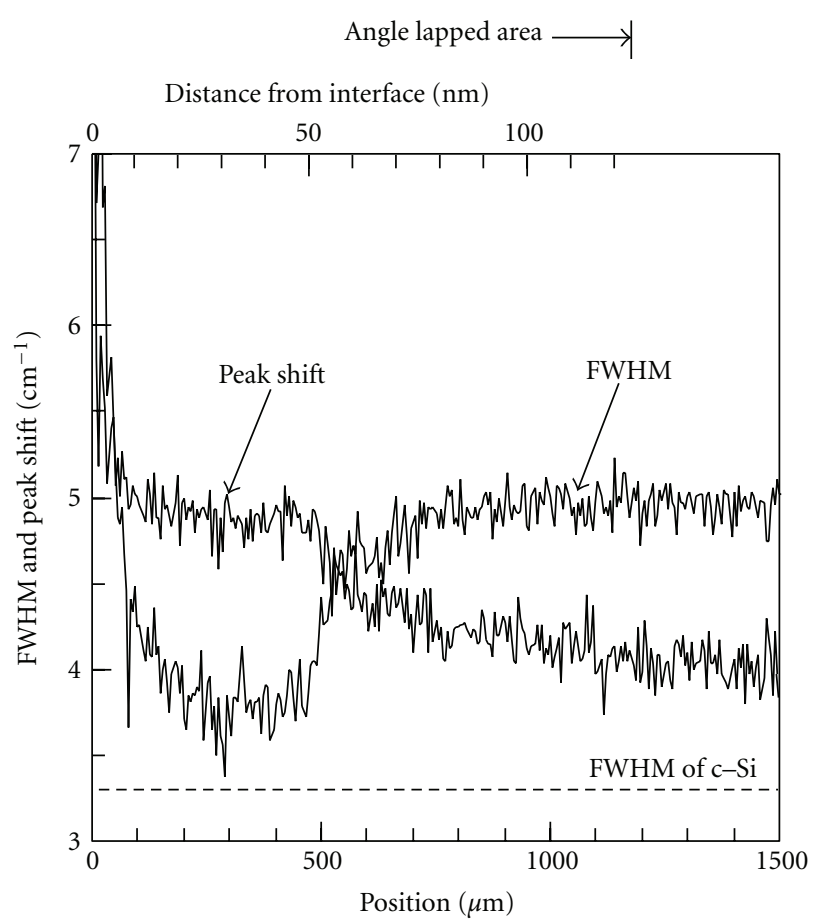

FIGURE 12: Distribution of the FWHM and lower-frequency peak shift of the OPM on the lapped surface of ELC poly-Si, which is the same as Figure 10.

either or both the $\sim 2000$ and $\sim 2100 \mathrm{~cm}^{-1}$ LVMs were found after plasma hydrogenation and $\mathrm{H}$-ion implantation [3739]. LVMs were also found for $\mathrm{H}$-terminated $\mathrm{c}-\mathrm{Si}$ surfaces [40]. In most cases, the $2000 \mathrm{~cm}^{-1}$ bands are broad (66$130 \mathrm{~cm}^{-1}$ ) with Gaussian shape. The $\sim 2100 \mathrm{~cm}^{-1}$ band tends to exhibit a Gaussian shape for broad bands (FWHM $\geq$ $80 \mathrm{~cm}^{-1}$ ) and a Lorentzian shape for narrow bands (FWHM $\leq 20 \mathrm{~cm}^{-1}$ ). Since the Gauss function is based on random statistics of phonon levels, the $2000 \mathrm{~cm}^{-1}$ band corresponds to $\mathrm{Si}-\mathrm{H}$ bonds with amorphous-like alignment.

In the case of ELC poly-Si, both $\sim 2000$ and $2100 \mathrm{~cm}^{-1}$ bands were found by Raman spectroscopy [18, 41]. A study of electron paramagnetic resonance demonstrated that isolated dangling bonds are condensed at the grain boundaries and effectively passivated by hydrogenation [42]. Furthermore, molecular dynamics simulation predicted that a few atomic layers of amorphous components reside at the grain boundary in covalent materials $[43,44]$. Thus, it was deduced that the appearance of Gaussian-shaped LVM reflects an amorphous-like structure around the grain boundaries.

Secco etching was performed to distinguish the generation sites of the 2000 and $2100 \mathrm{~cm}^{-1}$ bands. Figure 16 shows the variation of the 2000 and $2100 \mathrm{~cm}^{-1}$ LVM intensities with Secco etching time; hydrogenation was performed after the timed etching. It was shown that the $2000 \mathrm{~cm}^{-1} \mathrm{LVMs}$ rapidly disappear after a quick etching, while the $2100 \mathrm{~cm}^{-1}$ LVMs remained intense. This implies that the site of the $2000 \mathrm{~cm}^{-1}$ band is related to the grain boundaries preferentially removed by the etching, and the site of $2100 \mathrm{~cm}^{-1}$ band is other than grain boundaries. The increase of the $2100 \mathrm{~cm}^{-1}$

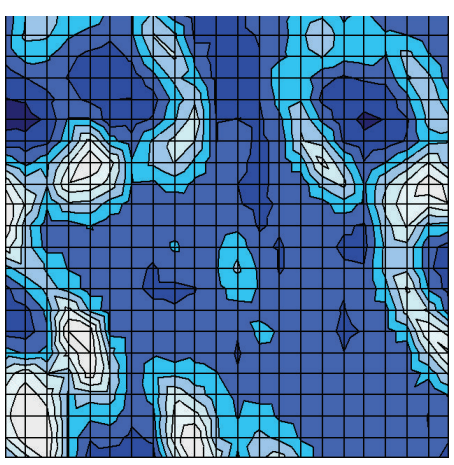

Intensity (a.u.)

$\begin{array}{ll}\square \text { 400-450 } & \square \text { 200-250 } \\ \square 350-400 & \square 150-200 \\ \square 300-350 & \square 100-150 \\ \square 250-300 & \square 50-100\end{array}$

(a)

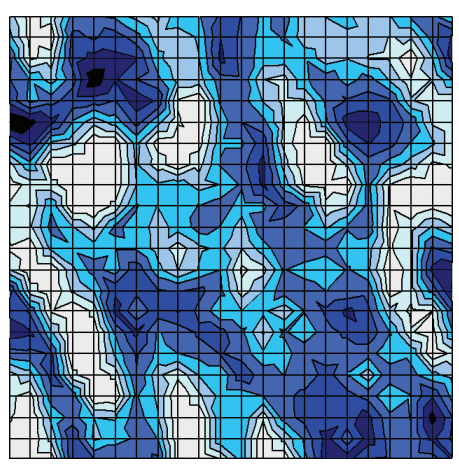

Peak shift $\left(\mathrm{cm}^{-1}\right)$

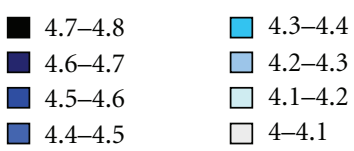

(b)
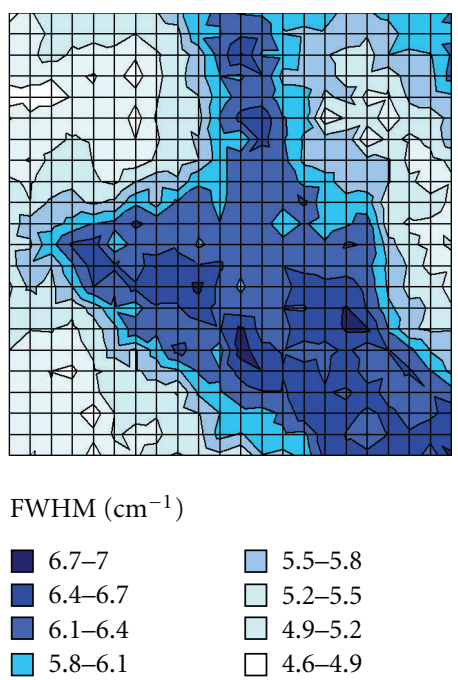

(c)

FIgURE 13: Two-dimensional maps of the OPM taken for the super lateral growth (SLG) region of the ELC film. 


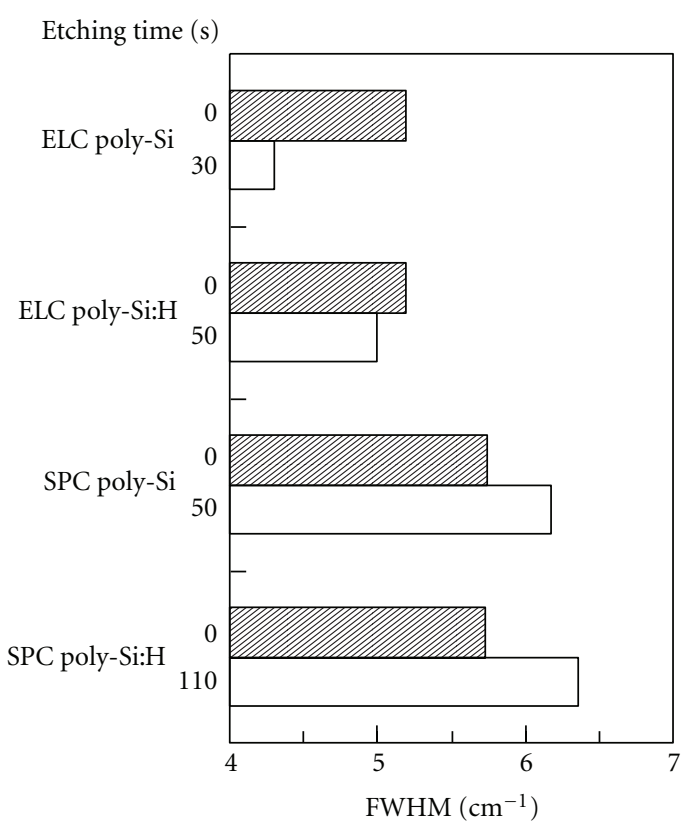

FIgURE 14: The FWHM of the OPM for poly-Si films before and after Secco etching.

band intensity at the late stage of etching might be attributed to the enhanced Raman scattering due to roughening of the ingrains after etching. The $2100 \mathrm{~cm}^{-1}$ band intensity tends to increase with hydrogenation time. Thus, this band was attributed to the breaking and termination of weak bonds in grains by hydrogenation.

As shown above, Si-H-related LVMs are useful to observe defects around the grain boundaries and ingrain. However, the LVM intensity is extremely small, and its detection relies to enhancement of Raman scattering as seen in ELC poly-Si.

\section{Initial Stage of Solid-Phase Crystallization}

Raman spectroscopy is useful to characterize the initial stage of crystallization because different phonon modes are induced by amorphous, nanocrystal, and crystal components in spectra.

The OPM spectra for a-Si and SPC poly-Si films were shown in Figures 5(a) and 5(b). For a-Si, four phonon modes of transverse-acoustic (TA), longitudinal-acoustic (LA), longitudinal-optical (LO), and TO appear at 150, 310, 380 , and $480 \mathrm{~cm}^{-1}$, respectively. The FWHM of the TO phonon mode is distributed between 60 and $80 \mathrm{~cm}^{-1}$ and reflects the fluctuation of the bond angles among $\mathrm{Si}$ in a-Si [45]. The presence of $\mathrm{H}$ in a-Si relaxes the strain and enhances the structural order. Figure 17 shows the variation of the FWHM of the TO phonon mode and intensity of the $2000 \mathrm{~cm}^{-1}$ LVM with dehydrogenation and hydrogenation for PE-CVD a-Si:H. The FWHM increased after dehydrogenation at $450^{\circ} \mathrm{C}$ for $30 \mathrm{~min}$ and recovered after rehydrogenation, that accompanied decrease and increase of the Si-H-related $2000 \mathrm{~cm}^{-1}$ band intensity, respectively. Thus, it was confirmed that the FWHM of the TO mode

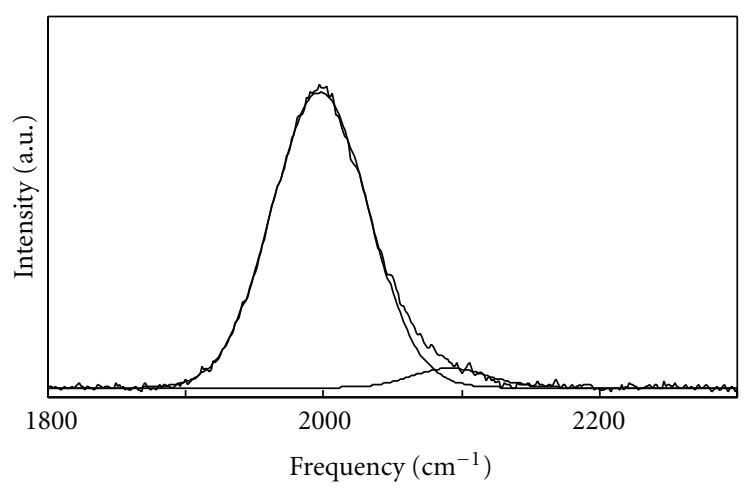

(a)

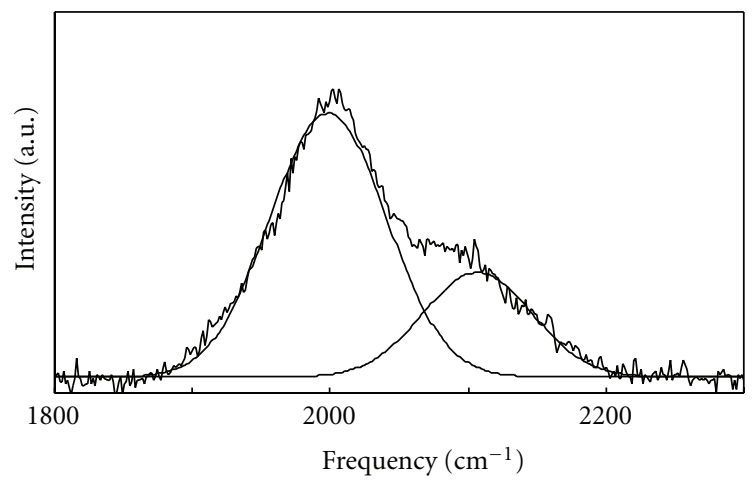

(b)

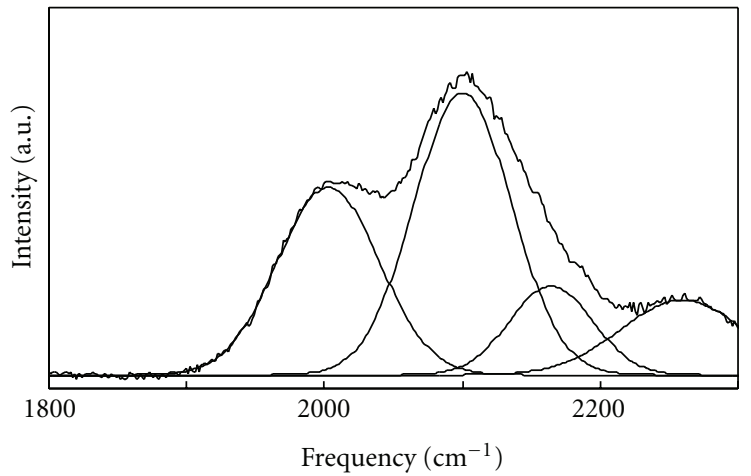

(c)

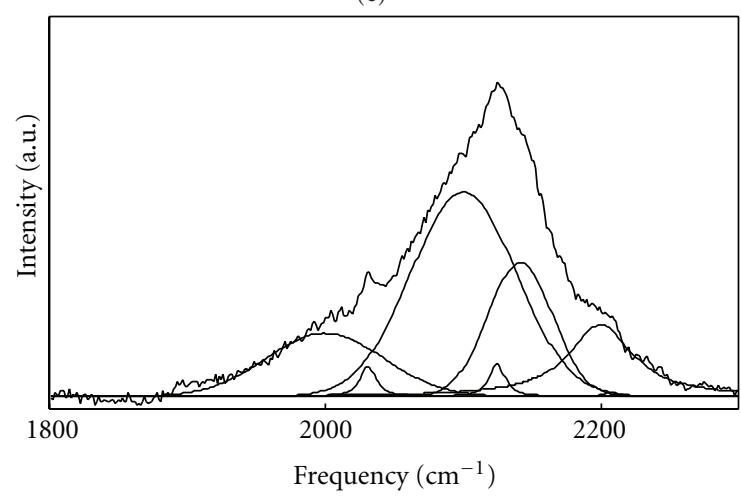

(d)

FIGURE 15: Si-H LVM for various Si films; (a) spectrum of aSi:H deposited by PECVD, (b) spectrum of hydrogenated ELC poly-Si, (c) spectrum of cat-CVD nanocrystalline $\mathrm{Si}$, and (d) spectrum of the ELC poly-Si irradiated with $\mathrm{O}_{2}$ plasma followed by hydrogenation. 


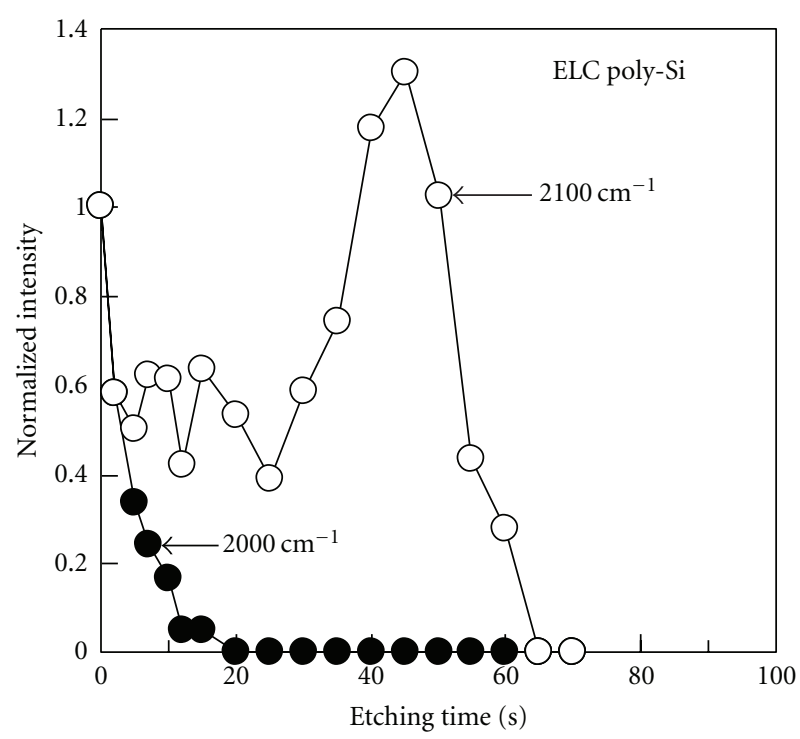

FIgURE 16: Variation of the intensities on the $2000 \mathrm{~cm}^{-1}$ and $2100 \mathrm{~cm}^{-1}$ LVMs with etching time. The intensity of both bands is normalized with the intensity at $0 \mathrm{~s}$.

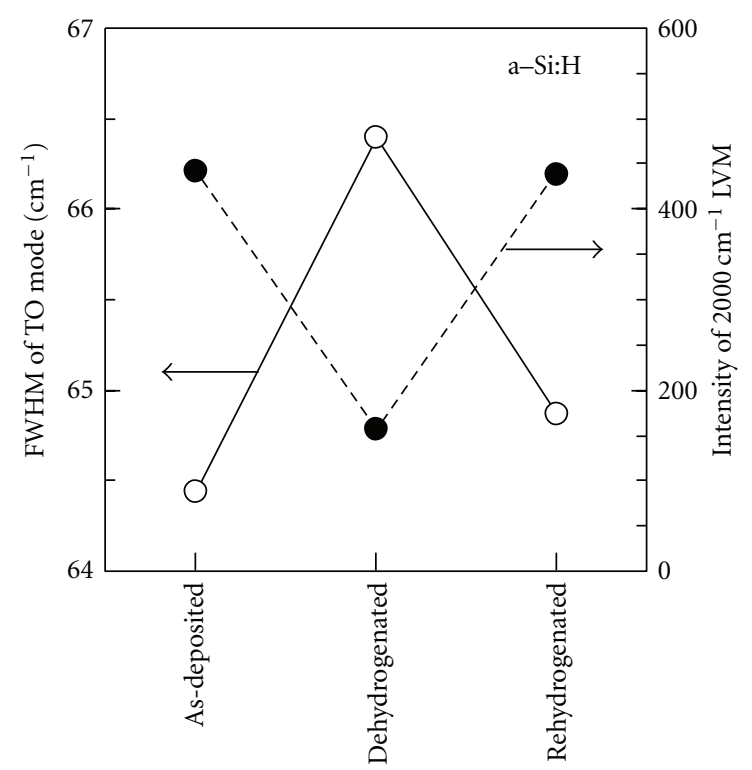

FIgUre 17: The variation of the FWHM of the TO phonon mode and $2000 \mathrm{~cm}^{-1}$ LVM intensity with dehydrogenation and rehydrogenation of a-Si:H film.

reflects the ordering of lattice structure owing to the $\mathrm{H}$ termination.

For Raman spectroscopy, the volume fraction of the crystal was estimated by the area-intensity ratio of the amorphous $\left(I_{a}\right)$ and crystal components $\left(I_{c}\right)$ (i.e., $I_{c} /\left(I_{c}+I_{a}\right)$ ) to obtain a relative value. [46-48]. Due to the differences in the Raman cross-section and absorption coefficient between amorphous and crystalline components, a calibration factor should be introduced. The presence of a nanocrystal should also be taken into account. Another method to estimate

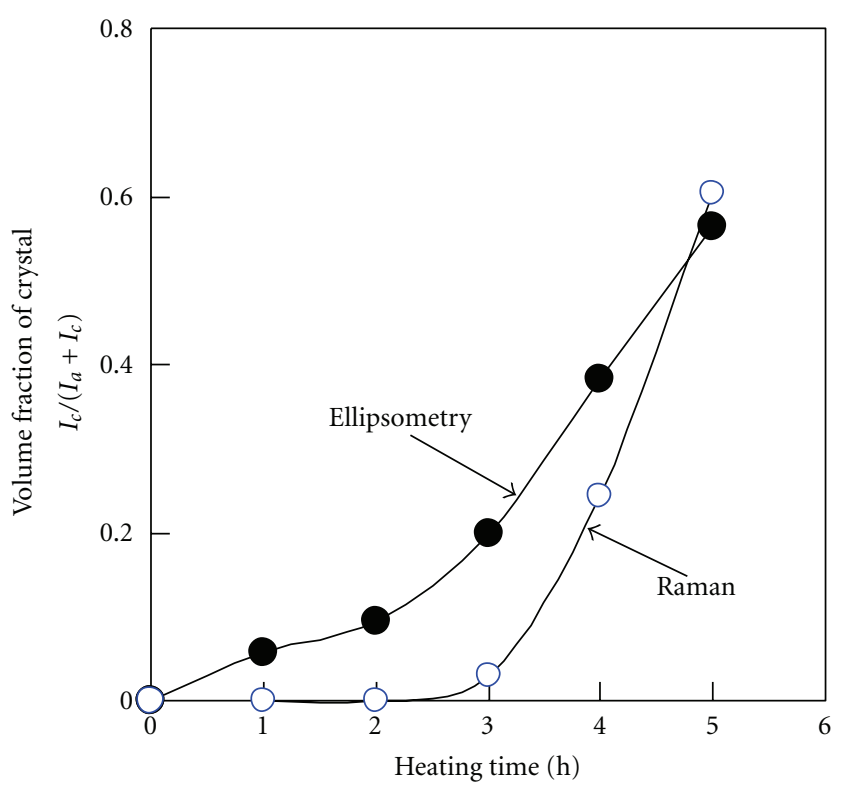

FIGURE 18: The variation of the crystal fraction in Si film with SPC time; the heating was performed at $580^{\circ} \mathrm{C}$. The volume fraction of crystal was estimated by spectroscopic ellipsometry. The intensity fraction of crystal components of the OPM in Raman spectra, $I_{c} /\left(I_{a}+I_{c}\right)$, is also plotted.

the volume fraction is spectroscopic ellipsometry. Figure 18 shows the heating time dependence of the crystal fraction in films as estimated by ellipsometry. The area intensity fraction of the crystal component, $I_{c} /\left(I_{c}+I_{a}\right)$, was also plotted there. An increase of the crystal fraction was observed even in the latent time when no crystals were found in the Raman spectra. Thus, the enhancement of the crystal fraction observed in ellipsometry is attributed to the realignment of $\mathrm{Si}$ atoms resulting in an increase of the $\mathrm{Si}$ atomic density rather than to the progress of crystallization. Although Raman spectroscopy is not always suitable to quantitatively estimate the crystal fraction, that is useful to certainly detect an appearance of the crystal component.

\section{Application to Characterization of Device Process}

Plasma processing is insufficient for the Si device fabrication. The generation of multiple LVMs by $\mathrm{H}$ plasma irradiation or $\mathrm{H}$ implantation was detected by IR or Raman spectroscopy in other studies [33, 38]. Figure 15(d) shows the multiple LVMs observed for ELC poly-Si film after the hydrogenation using remote plasma. Such multiple LVMs were not found for cSi $\{100\}$ treated by the same procedure. The enhancement of Raman scattering by hillocks and ridges on ELC poly-Si leads to highly sensitive detection of damage induced by the plasma hydrogenation.

Even after the fabrication of devices, the poly-Si layer in top-gate type TFTs can be observed from the backside of the glass substrate. Figure 19 shows the optical microscope image for a poly-Si TFT test device and the Raman spectra for an 

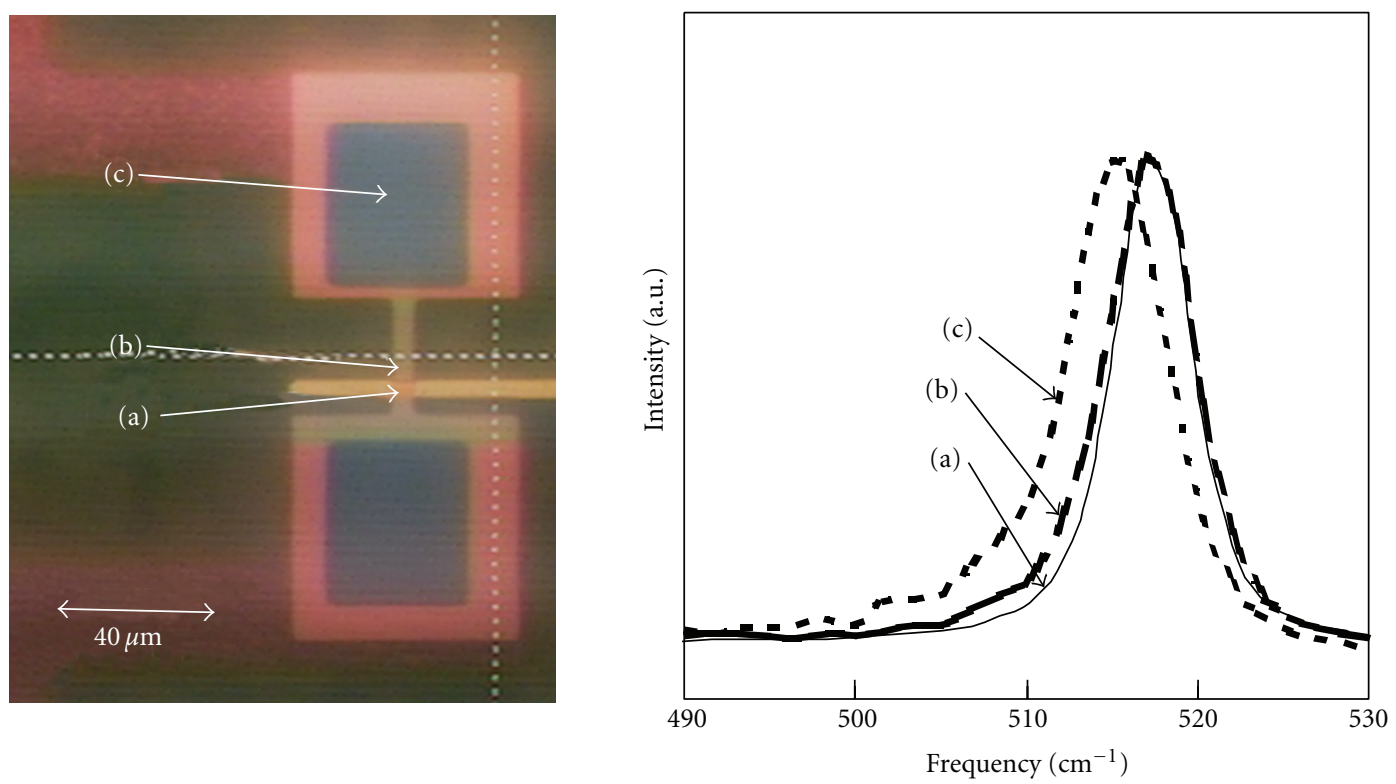

FIGURe 19: Photograph of the poly-Si TFT test device observed from the back of the glass substrate and Raman spectra taken for the (a) channel region, (b) lightly doped drain region, and (c) heavily doped drain region.

unintentionally doped channel region, a lightly doped drain region, and a heavily doped drain region. The spectrum for region (b) is slightly broadened at lower frequency. The spectrum for the region (c) shifts to a lower frequency and has enhanced asymmetry. These variations in the spectra with impurity doping were attributed to the Fano effect [49].

\section{Conclusions}

Raman microscopy for poly-Si thin films on glass substrates was described. The analysis of the spectra was performed by comparing the results with SEM, TEM, AFM, and spectroscopic ellipsometry. The principle factors of the Raman spectra were the FWHM and peak shift of the OPM. Basic models for analysis were the lowering of the spatial correlation due to large density defects and the thermal stress induced in films.

In the case of SPC poly-Si, the TEM image reveals large amount of the microtwins in the grains. The density of the microtwins is large enough to reduce the space correlation resulting in increase of FWHM.

Effects of the polarization, the interference of light in thin film, and the surface morphology were demonstrated as factors to determine the Raman scattering intensity of poly$\mathrm{Si}$ thin films. In the case of ELC poly-Si, Raman spectrum strongly reflects defects and stress around grain boundaries, which is due to enhancement of Raman scattering by hillocks and ridges. Such correlation between the intensity and morphology was confirmed by two-dimensional mapping with high spatial resolution. Defects around grain boundaries were detected as increase in FWHM of the OPM in Raman spectra, which was confirmed with decrease in FWHM by removing of those defects using Secco etching.
The combination of the hydrogenation of the films and observation of Si-H LVMs was shown to be useful to supplement the information on defects. The resultant $2000 \mathrm{~cm}^{-1}$ band was attributed to amorphous-like structures around the grain boundary, whereas the $2100 \mathrm{~cm}^{-1}$ band was mainly due to weak bonds in the grains, which were broken by extrinsic $\mathrm{H}$ followed by termination with $\mathrm{H}$.

Raman microscopy is also useful to detect plasma damage suffered during device processing, which results in the appearance of multiple Si-H LVMs after hydrogenation. Furthermore, Raman microscopy can be applied to characterize poly-Si films in TFT structures after device fabrication.

\section{Acknowledgment}

This research was partly funded by the Japan Society for the Promotion of Science (Grant-in-Aid for Scientific Research, (C) 21560329).

\section{References}

[1] J. G. Blake, M. C. King, J. D. Stevens, and R. Young, "Lowtemperature polysilicon reshapes FPD production," Solid State Technology, vol. 40, no. 5, pp. 151-161, 1997.

[2] H. Hayashi, T. Noguchi, and T. Oshima, "Polysilicon superthin-film transistor (SFT)," Japanese Journal of Applied Physics, vol. 23, no. 11, pp. 819-820, 1984.

[3] T. Sameshima, S. Usui, and M. Sekiya, "XeCl Excimer laser annealing used in the fabrication of poly-Si TFT's," Electron Device Letters, vol. 7, no. 5, pp. 276-278, 1986.

[4] J. S. Im and H. J. Kim, "Phase transformation mechanisms involved in excimer laser crystallization of amorphous sillicon films," Applied Physics Letters, vol. 63, pp. 1969-1971, 1993.

[5] A. Hara, F. Takeuchi, M. Takei et al., "High-performance polycrystalline silicon thin film transistors on non-alkali glass 
produced using continuous wave laser lateral crystallization," Japanese Journal of Applied Physics, vol. 41, no. 3 B, pp. L311L313, 2002.

[6] H. Matsumura, Y. Tashiro, K. Sasaki, and S. Furukawa, "Hall mobility of low-temperature-deposited polysilicon films by catalytic chemical vapor deposition method," Japanese Journal of Applied Physics, vol. 33, no. 9 A, pp. L1209-L1211, 1994.

[7] K. Kitahara, A. Hara, K. Nakajima, and M. Okabe, "Siliconhydrogen bonds in laser-crystallized polysilicon thin films and their effects on electron mobility," Japanese Journal of Applied Physics, vol. 38, no. 3 A, pp. 1320-1325, 1999.

[8] F. Secco d' Aragona, "Dislocation etch for (100) planes in silicon," Journal of the Electrochemical Society, vol. 119, no. 7, pp. 948-951, 1972.

[9] S. P. S. Porto and D. L. Wood, "Ruby optical maser as a raman source," Journal of the Optical Society of America, vol. 52, no. 3, pp. 251-252, 1962.

[10] G. E. Jellison Jr., "Spectroscopic ellipsometry data analysis: measured versus calculated quantities," Thin Solid Films, vol. 313-314, pp. 33-39, 1998.

[11] A. Nakamura, F. Emoto, E. Fujii et al., "Analysis of solid phase crystallization in amorphized polycrystalline Si films on quartz substrates," Journal of Applied Physics, vol. 66, no. 9, pp. 4248-4251, 1989.

[12] D. J. McCulloch and S. D. Brotherton, "Surface roughness effects in laser crystallized polycrystalline silicon," Applied Physics Letters, vol. 66, p. 2060, 1995.

[13] Z. Iqbal, S. Vepřek, A. P. Webb, and P. Capezzuto, "Raman scattering from small particle size polycrystalline silicon," Solid State Communications, vol. 37, no. 12, pp. 993-996, 1981.

[14] H. Richter, Z. P. Wang, and L. Ley, "The one phonon Raman spectrum in microcrystalline silicon," Solid State Communications, vol. 39, no. 5, pp. 625-629, 1981.

[15] E. Anastassakis, "Strain characterization of polycrystalline diamond and silicon systems," Journal of Applied Physics, vol. 86, no. 1, pp. 249-258, 1999.

[16] S. Higashi, N. Ando, K. Kamisako, and T. Sameshima, "Stress in pulsed-laser-crystallized silicon films," Japanese Journal of Applied Physics, vol. 40, no. 2 A, pp. 731-735, 2001.

[17] P. Lengsfeld, N. H. Nickel, C. Genzel, and W. Fuhs, "Stress in undoped and doped laser crystallized poly-Si," Journal of Applied Physics, vol. 91, no. 11, p. 9128, 2002.

[18] K. Kitahara, R. Yamazaki, T. Kurosawa, K. Nakajima, and A. Moritani, "Analysis of stress in laser-crystallized polysilicon thin films by Raman scattering spectroscopy," Japanese Journal of Applied Physics, vol. 41, no. 8, pp. 5055-5059, 2002.

[19] T. Englert, G. Abstreiter, and J. Pontcharra, "Determination of existing stress in silicon films on sapphire substrate using Raman spectroscopy," Solid State Electronics, vol. 23, no. 1, pp. 31-33, 1980.

[20] S. Adachi, Prosperities of Group-IV, III-V and II-VI Semiconductors, John Wiley \& Sons, Chichester, UK, 2006.

[21] G. K. White, in Thermal expansion of reference materials, C. Y. Ho, Ed., vol. 61, p. 277, ASM International, Ohio, Ohio, USA, 1998.

[22] K. Mizoguchi and S. I. Nakashima, "Determination of crystallographic orientations in silicon films by Raman-microprobe polarization measurements," Journal of Applied Physics, vol. 65, no. 7, pp. 2583-2590, 1989.

[23] K. Mizoguchi, S. Nakashima, Y. Sugiura, and H. Harima, "Micro-Raman characterization of crystallinity of laserrecrystallized silicon films on $\mathrm{SiO}_{2}$ insulators," Journal of Applied Physics, vol. 85, no. 9, pp. 6758-6762, 1999.

[24] K. Kitahara, H. Ogasawara, J. Kambara, M. Kobata, and Y. Ohashi, "Characterization of defects in polycrystalline silicon thin films using chemical etching, hydrogenation, and Raman spectroscopy," Japanese Journal of Applied Physics, vol. 47, no. 1, pp. 54-58, 2008.

[25] A. Otto, I. Mrozek, H. Grabhorn, and W. Akemann, "Surfaceenhanced Raman scattering," Journal of Physics: Condensed Matter, vol. 4, no. 5, article 001, pp. 1143-1212, 1992.

[26] M. Fleischmann, P. J. Hendra, and A. J. McQuillan, "Raman spectra of pyridine adsorbed at a silver electrode," Chemical Physics Letters, vol. 26, no. 2, pp. 163-166, 1974.

[27] J. A. Sánchez-Gil and J. V. García-Ramos, "Calculations of the direct electromagnetic enhancement in surface enhanced Raman scattering on random self-affine fractal metal surfaces," Journal of Chemical Physics, vol. 108, no. 1, p. 317, 1998.

[28] M. Sridharan, S. K. Narayandass, D. Mangalaraj, and H. C. Lee, "Effect of boron ion implantation on the structural and optical properties of polycrystalline Cd0.96Zn0.04Te thin films," Nuclear Instruments and Methods in Physics Research Section B, vol. 201, no. 3, pp. 465-474, 2003.

[29] P. Jayavel, S. Nakamura, R. Kesavamoorthy et al., "Surface morphology effects on the optical phonon modes in InAs xSb1-x epilayers on GaAs(001)," Physica Status Solidi B, vol. 243, no. 4, pp. R19-R21, 2006.

[30] L. Cao, B. Nabet, and J. E. Spanier, "Enhanced Raman scattering from individual semiconductor nanocones and nanowires," Physical Review Letters, vol. 96, no. 15, Article ID 157402, pp. 1-4, 2006.

[31] M. H. Brodsky, M. Cardona, and J. J. Cuomo, "Infrared and Raman spectra of the silicon-hydrogen bonds in amorphous silicon prepared by glow discharge and sputtering," Physical Review B, vol. 16, no. 8, pp. 3556-3571, 1977.

[32] H. Wagner and W. Beyer, "Reinterpretation of the siliconhydrogen stretch frequencies in amorphous silicon," Solid State Communications, vol. 48, no. 7, pp. 585-587, 1983.

[33] M. Stavola, S. J. Pearton, and J. W. Corbett, in Vibrational spectroscopy of hydrogen-related defects in silicon, J. I. Pankove and N. M. Johnson, Eds., vol. 34, pp. 139-183, Academic Press, New York, NY, USA, 1991.

[34] W. Beyer, in Hydrogen phenomena in hydrogenated amorphous silicon, N. H. Nickel, Ed., vol. 61, pp. 165-239, Academic Press, New York, NY, USA, 1999.

[35] M. Cardona, "Vibrational spectra of hydrogen in silicon and germanium," Physica Status Solidi B, vol. 118, no. 2, pp. 463481, 1983.

[36] C. C. Tsai, in Plasma deposition of amorphous and crystalline silicon, H. Fritzsche, Ed., pp. 123-147, World Scientific, Singapore, 1988.

[37] K. Murakami, N. Fukata, S. Sasaki et al., "Hydrogen molecules in crystalline silicon treated with atomic hydrogen," Physical Review Letters, vol. 77, no. 15, pp. 3161-3164, 1996.

[38] H. J. Stein, "Vacancies and the chemical trapping of hydrogen in silicon," Physical Review Letters, vol. 43, no. 14, pp. 10301033, 1979.

[39] M. Kitajima, K. Ishioka, K. Nakanoya et al., "Three different forms of hydrogen molecules in silicon," Japanese Journal of Applied Physics, vol. 38, no. 7 A, pp. L691-L693, 1999.

[40] Y. J. Chabal, "High-resolution infrared spectroscopy of adsorbates on semiconductor surfaces: hydrogen on $\mathrm{Si}(100)$ and Ge(100)," Surface Science, vol. 168, no. 1-3, pp. 594-608, 1986.

[41] N. H. Nickel and K. Brendel, "Hydrogen bonding and grainboundary defects in laser crystallized poly-Si," Solid State Phenomena, vol. 93, pp. 191-196, 2003.

[42] N. H. Nickel, A. Yin, and S. J. Fonash, "Influence of hydrogen and oxygen plasma treatments on grain-boundary defects in polycrystalline silicon," Applied Physics Letters, vol. 65, no. 24, pp. 3099-3101, 1994. 
[43] P. Keblinski, S. R. Phillpot, D. Wolf, and H. Gleiter, "On the thermodynamic stability of amorphous intergranular films in covalent materials," Journal of the American Ceramic Society, vol. 80, no. 3, pp. 717-732, 1997.

[44] K. Sugio and H. Fukushima, "Molecular dynamics studies of crystallization and grain boundary formation in silicon," Solid State Phenomena, vol. 93, pp. 381-386, 2003.

[45] J. S. Lamin, in Raman scattering of amorphous Si, Ge, and their alloys, J. I. Pankove, Ed., pp. 159-195, Academic Press, New York, NY, USA, 1984.

[46] H. Kakinuma, M. Mohri, M. Sakamoto, and T. Tsuruoka, "Structural properties of polycrystalline silicon films prepared at low temperature by plasma chemical vapor deposition," Journal of Applied Physics, vol. 70, no. 12, pp. 7374-7381, 1991.

[47] T. Okada, T. Iwaki, H. Kasahara, and K. Yamamoto, "Probing the crystallinity of evaporated silicon films by Raman scattering," Japanese Journal of Applied Physics, vol. 24, no. 2, pp. 161165, 1985.

[48] C. Smit, R. A. C. M. M. Van Swaaij, H. Donker, A. M. H. N. Petit, W. M. M. Kessels, and M. C. M. Van de Sanden, "Determining the material structure of microcrystalline silicon from Raman spectra," Journal of Applied Physics, vol. 94, no. 5, pp. 3582-3588, 2003.

[49] N. Nakano, L. Marville, and R. Reif, "Raman scattering in polycrystalline silicon doped with boron," Journal of Applied Physics, vol. 72, no. 8, pp. 3641-3647, 1992. 


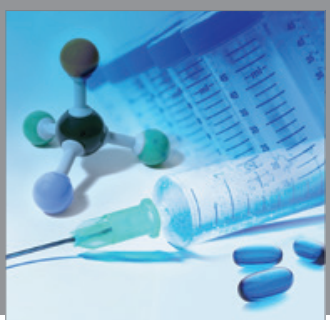

International Journal of

Medicinal Chemistry

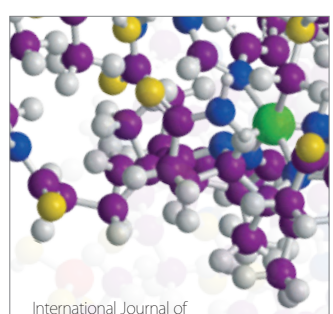

Carbohydrate Chemistry

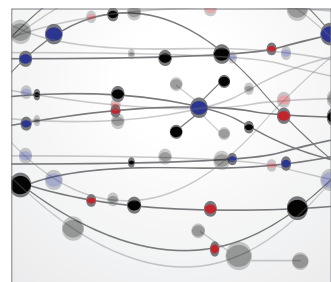

The Scientific World Journal
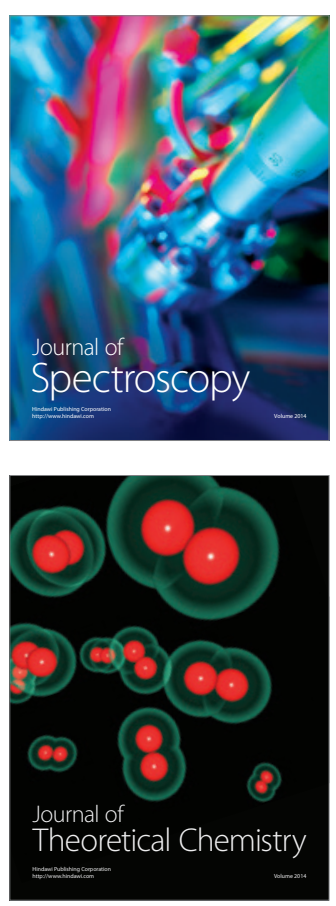
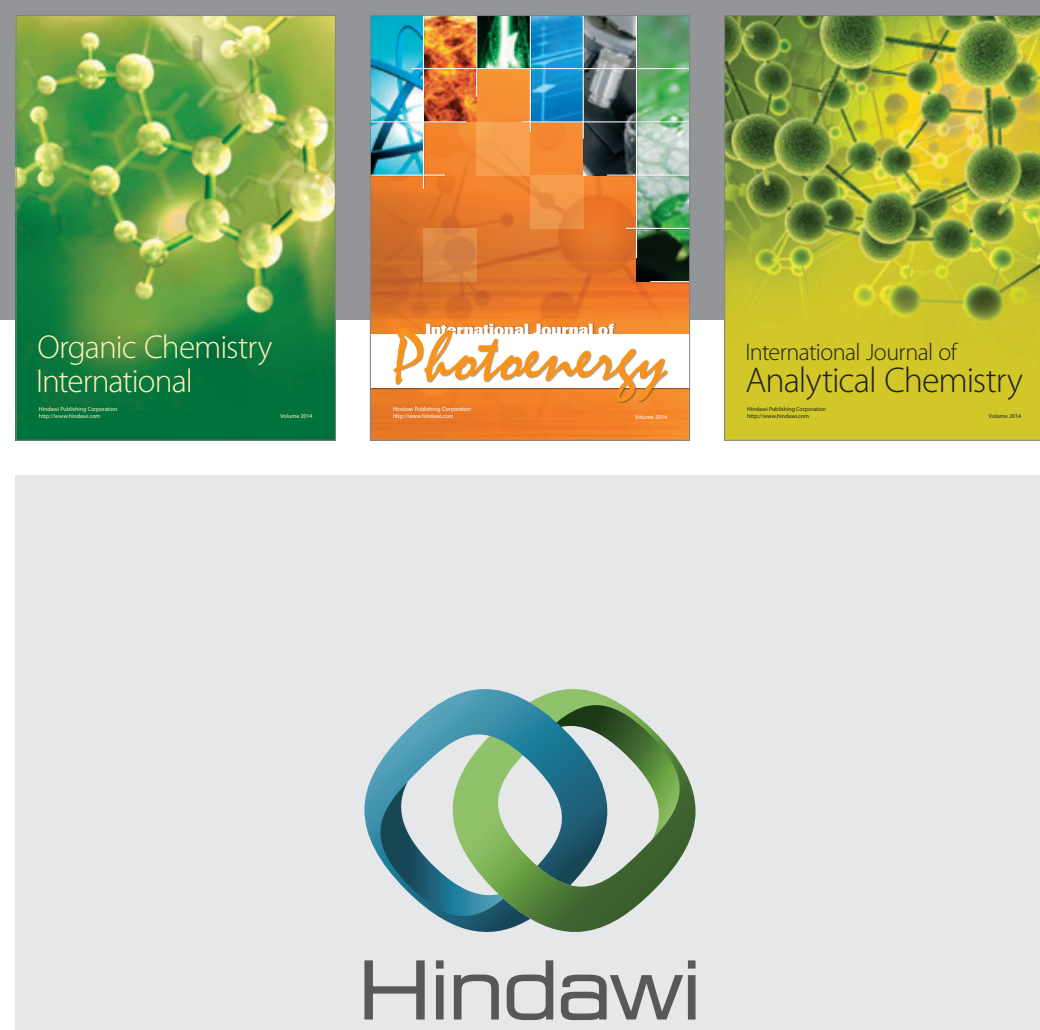

Submit your manuscripts at

http://www.hindawi.com
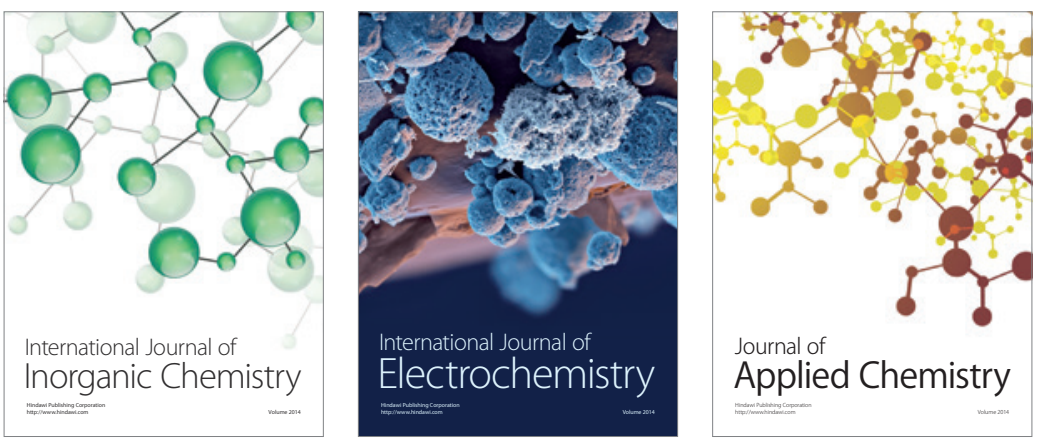

Journal of

Applied Chemistry
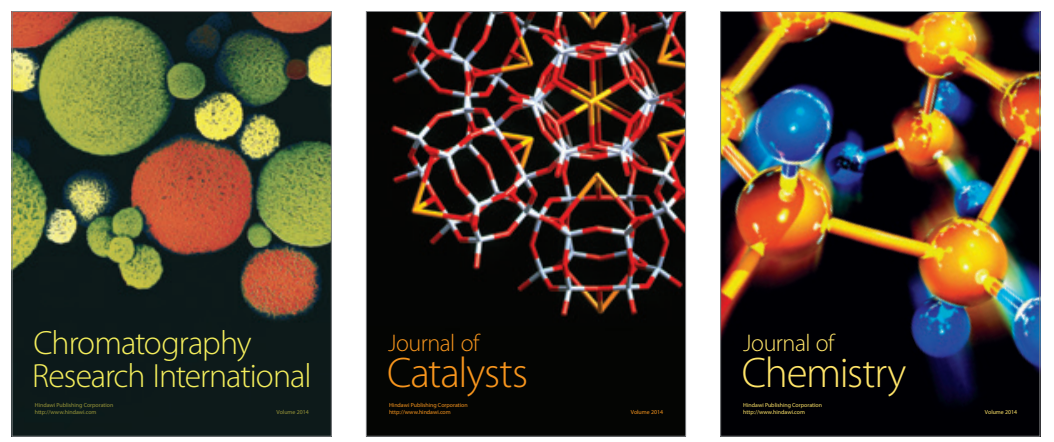
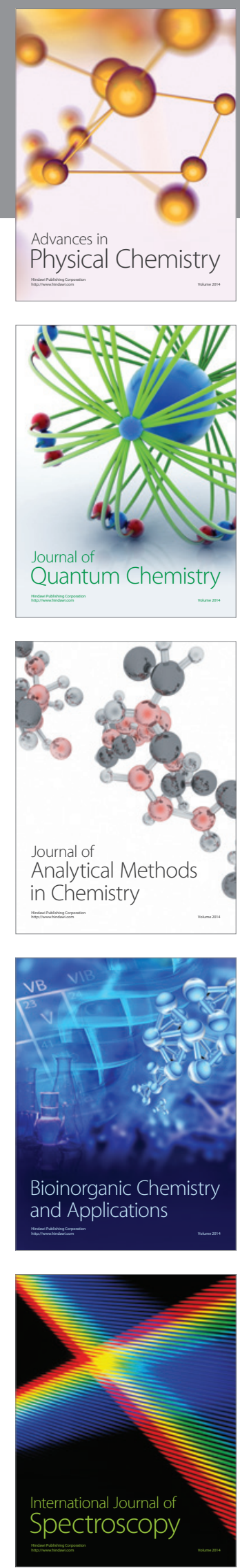